\title{
Biodegradable Polymers
}

\author{
Babak Ghanbarzadeh and Hadi Almasi \\ Additional information is available at the end of the chapter \\ http://dx.doi.org/10.5772/56230
}

\section{Introduction}

In developing countries, environmental pollution by synthetic polymers has assumed dangerous proportions. Petroleum-derived plastics are not readily biodegradable and because of their resistance to microbial degradation, they accumulate in the environment. In addition in recent times oil prices have increased markedly. These facts have helped to stimulate interest in biodegradable polymers. Biodegradable plastics and polymers were first introduced in 1980s. Polymers from renewable resources have attracted an increasing amount of attention over the last two decades, predominantly due to two major reasons: firstly environmental concerns, and secondly the realization that our petroleum resources are finite. There are many sources of biodegradable plastics, from synthetic to natural polymers. Natural polymers are available in large quantities from renewable sources, while synthetic polymers are produced from non-renewable petroleum resources. Biodegradation of polymeric biomaterials involves cleavage of hydrolytically or enzymatically sensitive bonds in the polymer leading to polymer erosion. A vast number of biodegradable polymers have been synthesized recently and some microorganisms and enzymes capable of degrading them have been identified.

The objective of this chapter is to classification of biodegradable polymers. The chemical structure, sources, production and synthesis methods, physical properties (mechanical, barrier and thermal properties) and applications of most important biodegradable polymers would be discussed.

\section{Classification and properties of biodegradable polymers}

The biodegradable polymers can be classified according to their chemical composition, origin and synthesis method, processing method, economic importance, application, etc. In the 


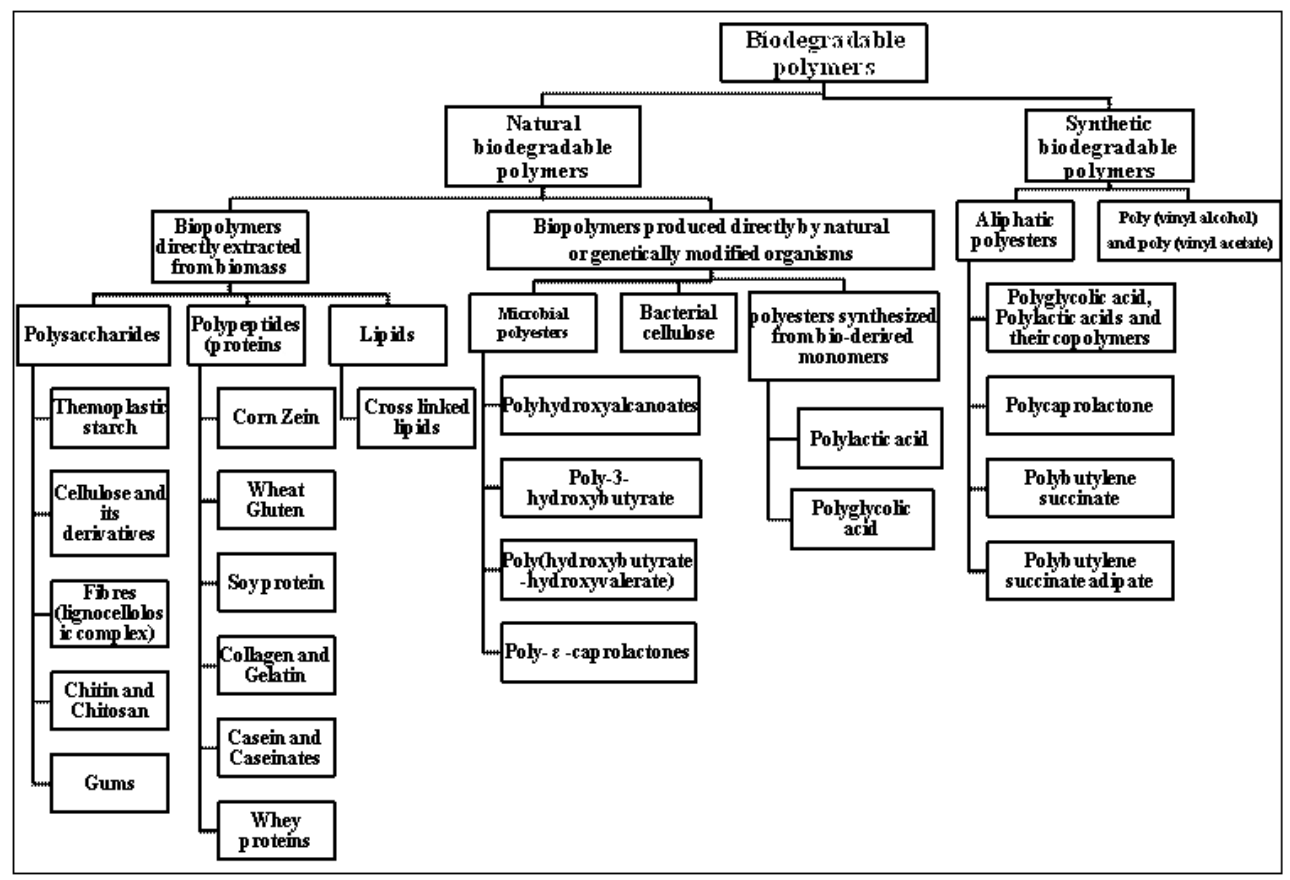

Figure 1. Schematic presentation of biobased polymers based on their origin and method of production

present chapter, biodegradable polymers classified according to their origin into two groups: natural polymers which obtained from natural resources and synthetic polymers which produced from oil. An overview of these categories is given in Fig. 1.

\subsection{Natural biodegradable polymers}

Biopolymers are polymers formed in nature during the growth cycles of all organisms; hence, they are also referred to as natural polymers. Their synthesis generally involves enzymecatalyzed, chain growth polymerization reactions of activated monomers, which are typically formed within cells by complex metabolic processes.

\subsubsection{Biopolymers directly extracted from biomass}

\subsubsection{Polysaccharides}

For materials applications, the principal polysaccharides of interest are cellulose and starch, but increasing attention is being given to the more complex carbohydrate polymers produced by bacteria and fungi, especially to polysaccharides such as xanthan, curdlan, pullulan and hyaluronic acid. These latter polymers generally contain more than one type of carbohydrate unit, and in many cases these polymers have regularly arranged branched structures. Because 
of this difference, enzymes that catalyze hydrolysis reactions during the biodegradation of each kind of polysaccharides are different and are not interchangeable.

\subsection{Thermoplastic starch}

Starch is the major polysaccharide reserve material of photosynthetic tissues and of many types of plant storage organs such as seeds and swollen stems. The principal crops used for its production include potatoes, corn and rice. In all of these plants, starch is produced in the form of granules, which vary in size and somewhat in composition from plant to plant (Chandra and Rustgi, 1998). The starch granule is essentially composed of two main polysaccharides, amylose and amylopectin with some minor components such as lipids and proteins. Amylose is essentially a linear molecule of $(1 \rightarrow 4)$-linked $\alpha$-D-glucopyranosyl units with some slight branches by $(1 \rightarrow 6)$ - $\alpha$-linkages (Fig. 2). Typically, amylose molecules have molecular weights ranging from $10^{5}$ to $10^{6} \mathrm{gmol}^{-1}$ (Buleon et al., 1998). Amylopectin is a highly branched molecule composed of chains of $\alpha$-D- glucopyranosyl residues linked together mainly by $(1 \rightarrow 4)$-linkages but with $(1 \rightarrow 6)$ linkages at the branch points. Amylopectin consist of hundreds of short chains of $(1 \rightarrow 4)$-linked $\alpha$-D-glucopyranosyl interlinked by $(1 \rightarrow 6)$ - $\alpha$-linkages (Fig. 2$)$. It is an extremely large and highly branched molecule (molecular weights ranging from $10^{6}$ to $10^{8} \mathrm{gmol}^{-1}$ ).

There are three types of crystallinity in starch. They are the 'A' type mainly cereal starches such as maize, wheat, and rice; 'B' type such as tuber starches (potato, sago); and finally the 'C' type crystallinity which is the intermediate between A and B type crystallinity, normally found in bean and other root starches (Blanshard, 1987). Another type of crystallinity is the Vh-type, which is the characteristic of amylose complexed with fatty acids and monoglycerides.

Starch granules contain alternating 120-400 nm amorphous and semi-crystalline layers or growth rings (Buleon et al., 1998). The semi-crystalline growth rings are composed of alternating amorphous and crystalline lamellae. The sum of one amorphous and one crystalline lamella is around 9-10 nm in size. Amylopectin is often presumed to support the framework of the semi- crystalline layers in the starch granule. The short chains with polymerization degrees ranging between 15 and 18 form a double helical conformation (Buleon et al., 1998) and associating into clusters. These clusters pack together to produce a structure of alternating crystalline and amorphous lamellar composition. The side chains clusters which are predominantly linear and form double helices are responsible for the crystalline lamellae while the branching regions of the amylopectin molecule are responsible for the amorphous lamellae.

Thermoplastic starch is plasticized starch that has been processed (typically using heat and pressure) to completely destroy the crystalline structure of starch to form an amorphous thermoplastic starch. Thermoplastic starch processing typically involves an irreversible orderdisorder transition termed gelatinization. Starch gelatinization is the disruption of molecular organization within the starch granules and this process is affected by starch-water interactions. Fig. 3 highlights the gelatinization process diagrammatically (Lai and Kokini, 1991). This figure shows raw starch granules made up of amylose (linear) and amylopectin (branched) molecules (step (a)). Then the addition of water breaks up crystallinity and disrupts helices (step (b)). Addition of heat and more water causes granules to swell and amylose diffuses out 


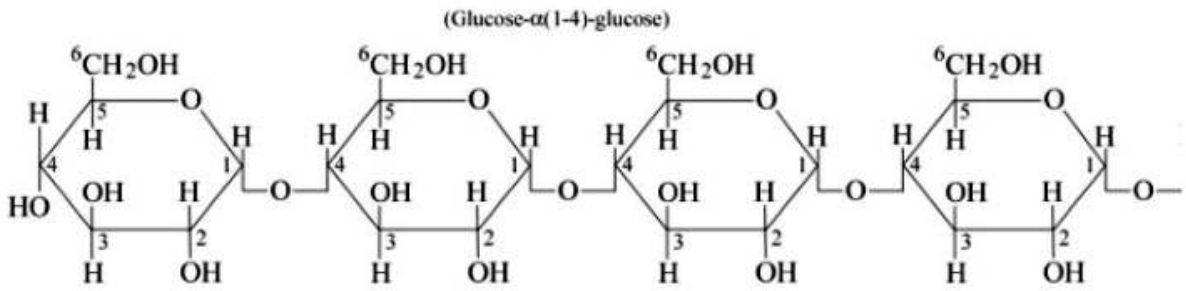

Amylose

(Glucose-ar (1-4)-glucose)

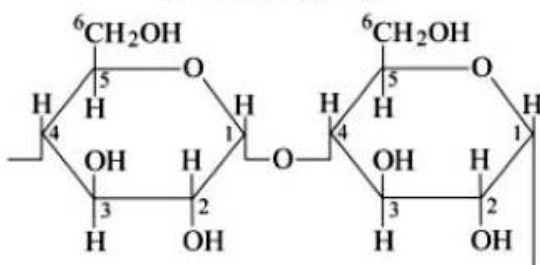

Branch point linkage

(Glucose-a(1-6)-glucose)

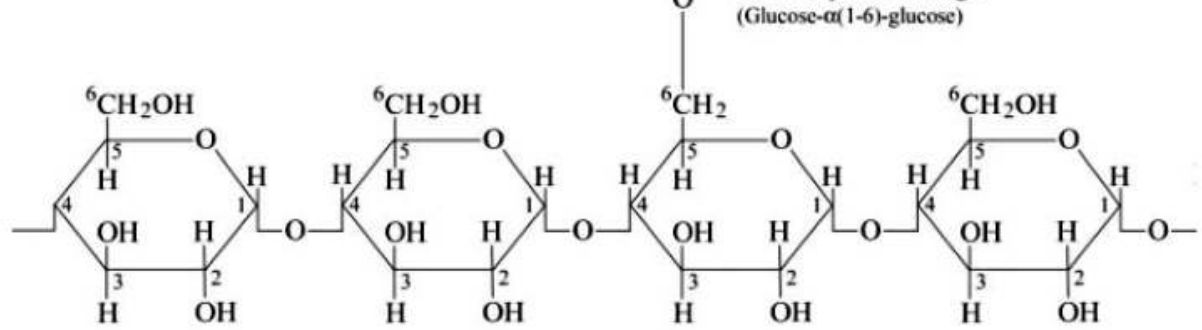

Amylopectin

Figure 2. Chemical structure of amylose and amylopectin (Buleon et al., 1998)

of the granule (step (c)). Granules, mostly containing amylopectin are collapsed and held in a matrix of amylose (step (d)).

Thermoplastic starch is produced using dry native starch with a swelling or plastifying agent in compound extruders without adding water. In extrusion, starch is converted by application of both thermal and mechanical energy, and basically three phenomena occur at different structural levels: fragmentation of starch granules; hydrogen bond cleavage between starch molecules, leading to loss of crystallinity; and partial depolymerization of the starch polymers (Fang and Fowler, 2003). Furthermore, the extrusion process ensures the very intimate mixing of the polymers and any additives. By introduction of mechanical energy and heat in a temperature range of $120-220{ }^{\circ} \mathrm{C}$, crystal starch, is homogenized and melted in an extrusion process with a plasticizer which lowers the melting point of the starch. With this process, a permanent conversion of the molecular structure to thermoplastic starch is performed (Lorcks, 
(a)

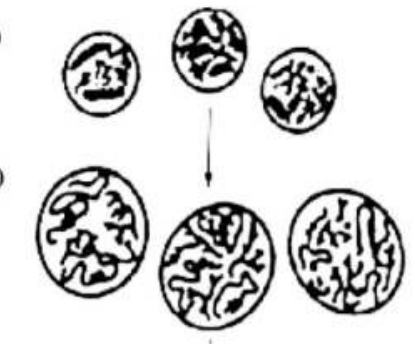

(c)

(d)

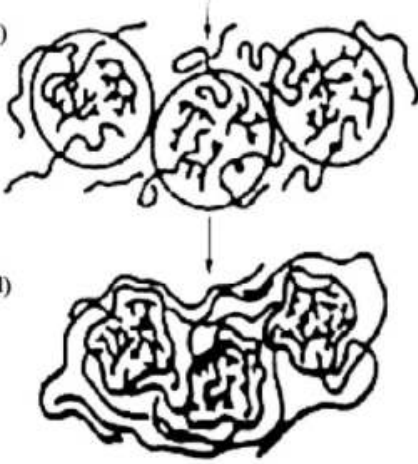

Figure 3. Starch gelatinization process (Lai and Kokini, 1991)

1998). The thermoplastic starch is free of crystalline fractions. Molecules such as polyglycols (e.g. glycerol, sorbitol, etc), amides and amines serve as non-volatile plasticizers for starch (Wiedersheim and Strobel, 1991).

Depending on the starch source and processing conditions, a thermoplastic material may be obtained with different properties suitable for various applications. Starch has been widely used as a raw material in film production because of increasing prices and decreasing availability of conventional film-forming resins (Chandra and Rustgi, 1998). Potential applications of starch films include production of disposable food serviceware, food packaging, purchase bags, composting bags and loose fill products (Xiong et al., 2008). Starch is also used in hygiene and cosmetics. Moreover, starch has been used for many years as an additive to plastic for various purposes. Starch was added as filler to various resin systems to make films that were impermeable to water but permeable to water vapour (Pedroso and Rosa, 2005). Starch as biodegradable filler in LDPE was reported (Nakamura et al., 2005). A starch-filled polyethylene film was prepared which becomes porous after the extraction of the starch. This porous film can be readily invaded by microorganisms and rapidly saturated with oxygen, thereby increasing polymer degradation by biological and oxidative pathways. Starch is also useful for making agricultural mulch films because it degrades into harmless products when placed in contact with soil microorganisms. Starch is also used in medical applications. For example, starch-based thermoplastic hydrogels for use as bone cements or drug-delivery carriers have 
been developed through blending starch with cellulose acetate (Pereira et al., 1998; Espigares et al., 2002).

Important properties of thermoplastic starch based materials include (Lorcks, 1998):

- compostable in accordance with DIN 54900

- high water vapour permeability

- good oxygen barrier

- not electrostatically chargeable

- low thermal stability

In general, the low resistance to water and the variations in mechanical properties under humid conditions affect the use of starch for various applications. As water has a plasticizing power, the material behavior changes according to the relative humidity of the air (Averous, 2002). Strong hydrophilic character (water sensitivity) and poor mechanical properties compared to conventional synthetic polymers are the most important disadvantages of starch which make it unsatisfactory for some applications such as packaging purposes. Generally, many approaches are suggested to mitigate these shortcomings. One approach is the modification of starch. Cross-linking can be produce low water sensitive and high strength materials (Ghanbarzadeh et al., 2010). According to Takore et al., (2001), the esterification of starch allows the increase of its thermoplastic characteristics, as well as its thermal stability. Other approach to improve the functional properties of the starch films is to blend starch with other polymers. Mao et al. (2000) examined the extrusion of thermoplastic cornstarch- glycerol-polyvinyl alcohol (PVOH) blends and noted the effect of $\mathrm{PVOH}$ to improve mechanical properties and slow biodegradation. Development of the polymer nanocomposites is one of the latest revolutionary steps of the polymer technology. In terms of nanocomposite reinforcement of thermoplastic starch polymers there has been much exciting new developments. Dufresne and Cavaille (1998) and Angles and Dufresne (2000) highlight work on the use of microcrystalline whiskers of starch and cellulose as reinforcement in thermoplastic starch polymer and synthetic polymer nanocomposites. They find excellent enhancement of properties, probably due to transcrystallisation processes at the matrix/fibre interface. Almasi et al. (2010) examined the use of nanoscale montmorillonite into starch/carboxymethyl cellulose blends and finds excellent improvements in film impermeability and tensile properties.

\subsection{Cellulose and its derivatives}

At present, cellulose is the most abundant polymer available worldwide with an estimated annual natural production of $1.5 \times 10^{12}$ tons and considered as an almost inexhaustible source of raw materials (Cao et al., 2009). Cellulose is composed of polymer chains consisting of unbranched $\beta(1 \rightarrow 4)$ linked D- glucopyranosyl units (anhydroglucose unit) (Fig. 4). The length of these $\beta(1 \rightarrow 4)$ glucan chains depends on the source of cellulose. As the main component of cell wall, cellulose is predominantly located in the secondary wall. In the primary cell wall, cellulose consists of roughly 6000 glucose units. Three hydroxyl groups, placed at the positions C2 and C3 (secondary hydroxyl groups) and C6 (primary hydroxyl groups) can form intra- 
and intermolecular hydrogen bonds (Abdul Khalil et al., 2012). Because of the strong tendency for intra- or intermolecular hydrogen bonding, bundles of cellulose molecules aggregate to microfibrils, which form either highly ordered (crystalline) or less ordered (amorphous) regions (Hamad, 2006). Microfibrils are further aggregated to fibrils and finally to cellulose fibers.

Cellulose is the main constituent of cell wall in lignocellulosic plant, and its content depends on the plant species, growing environment, position, growth, and maturity. Generally, cellulose content in lignocellulosic plant is $23-53 \%$ on a dry-weight basis, less than that in cotton, which is almost made of pure fibrous cellulose. In most straw species, approximately $35-45 \%$ of the dry substance is cellulose (Knauf and Moniruzzaman, 2004).

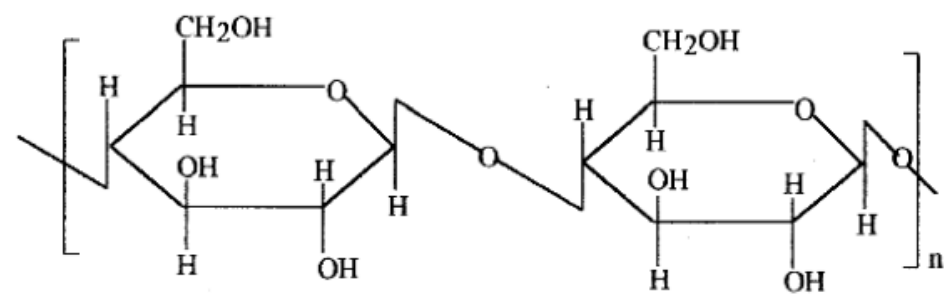

Figure 4. Chemical structure of cellulose

In the lignocellulosic materials, cellulose is embedded in a gel matrix composed of hemicelluloses, lignins, and other carbohydrate polymers. Cellulose was isolated for the first time some 150 years ago (Smith, 2005). The combination of the chemical and the mechanical treatments is necessary for the dissolution of lignins, hemicelluloses, and other noncellulosic substances. A protocol based on acidified sodium chlorite is frequently applied to delignify woody materials as an initial step in the isolation of cellulose. Alkali extraction to dissolve hemicelluloses before or after delignification is the common method. The presence of high amounts of lignin in isolated cellulose fibers after delignification affects the structure and properties of the cellulose fibers. Fibers with high amounts of lignin are coarse and stiff, and have a brownish color. Therefore, it is challenging to obtain fibers that are relatively free of bound lignin. To achieve this aim, chemical bleaching, which is used to obtain fibers with higher cellulose content from delignified and unbleached fibers, is usually considered as a continuation of delignification process to isolate cellulose from woody raw materials (Brendel et al., 2000). Nowadays, there are various procedures for extraction of cellulose microfibrils (e.g. pulping methods, acid hydrolysis, steam explosion, atc.)(Abdul Khalil et al., 2012).

Many useful properties stem from unique functional characteristics related to the chemical structure of cellulose. These structural properties include an extended, planar chain conformation and oriented, parallel-chain packing in the crystalline state. The absence of branches in this $100 \%$ linear polymer contributes to efficient chain packing in the native crystalline state, resulting in stiff, dimensionally stable fibers (Smith, 2005). Cellulose fibers thus exhibit a high 
degree of crystallinity (upwards of 70\%) when isolated and purified. However, cellulose fibers present in native woody biomass exhibit approximately $35 \%$ crystallinity, due to the presence of other lignocellulosic components (Abdul Khalil et al., 2012). The crystal nature (monoclinic sphenodic) of naturally occurring cellulose is known as cellulose I. Cellulose is resistant to strong alkali (17.5 $\mathrm{wt} \%)$ but is easily hydrolyzed by acid to water-soluble sugars. Cellulose is relatively resistant to oxidizing agents (John and Thomas, 2008). The tight fiber structure created by hydrogen bonds results in the typical material properties of cellulose, such as high tensile strength and insolubility in most solvents. There are significant differences between the properties of straw cellulose, wood cellulose, and cotton cellulose. The cellulose crystallites are longer in straw pulps than in wood pulps, but they are not as long as in cotton cellulose. In addition, the degree of crystallinity of straw pulps appears to be less than that of wood cellulose. Low crystallinity can be useful when a cellulose derivative is to be manufactured (Sun and Tomkinson, 2000).

Cellulose has received more attention than any other polymer since it is attacked by a wide variety of microorganisms. The biodegradation of cellulose is complicated, because cellulose exists together with lignin however, it is fortunate that pure cellulose does decompose readily (Chandra and Rustgi, 1998). Fermentation of cellulose has been suggested as a source of chemicals such as ethanol and acetic acid, but this has not achieved any commercial importance to date.

The most significant cellulosic applications are in the paper, wood product, textile, film, and fiber industries but recently it has also attracted significant interest as a source of biofuel production (Mantia and Morreale, 2011). The natural cellulosic carbon skeleton can be utilized in two major applications on an industrial scale. The first is as regenerated or mercerized cellulose (cellulose II, Rayon), which is not moldable and is used only for film and fiber production. The second represents a broader class of applications, which employs chemically modified celluloses, principally the cellulose esters (Chandra and Rustgi, 1998).

As mentioned before, in all forms, cellulose is a very highly crystalline, high molecular weight polymer, which is infusible and insoluble in all but the most aggressive, hydrogen bondbreaking solvents such as $N$-methylmorpholine- $N$-oxide. Because of its infusibility and insolubility, cellulose is usually converted into derivatives to make it more processable. All of the important derivatives of cellulose are reaction products of one or more of the three hydroxyl groups, which are present in each glucopyranoside repeating unit, including (Chandra and Rustgi, 1998):

- ethers, e.g. methylcellulose, hydroxypropyl methyl cellulose and hydroxylethyl cellulose;

- esters, e.g. cellulose acetate, carboxymethyl cellulose and cellulose xanthate, which is used as a soluble intermediate for processing cellulose into either fibre or film forms, during which the cellulose is regenerated by controlled hydrolysis;

- acetals, especially the cyclic acetal formed between the C2 and C3 hydroxyl groups and butyraldehyde. 
These modified forms of cellulose can be tailored to exhibit particular physical and chemical properties by varying the pattern and degrees of substitution within the cellulose backbone. Industrial applications are numerous and widespread for cellulose derivatives owing to rigidity, moisture vapor permeability, grease resistance, clarity, and appearance (Edgar et al., 2001). Esterification of the cellulose backbone provides structural changes that allow for a greatly expanded range of applications, not available to the parent polysaccharide. Commercially available forms of cellulose acetate have degrees of substitution between 1.7 and 3.0 and are currently used in high volume applications ranging from fibers, to films, to injection moulding thermoplastics, to low solids solvent-borne coatings for metal and automobile industries (Mohanty et al., 2000). Methylcellulose exhibits thermal gelation and has excellent film-forming properties. It has been widely used to prepare edible films (Debeaufort and Voilley, 1997; Peressini et al., 2003). Carboxymethyl cellulose is also widely used in the pharmaceutical and food industries. It has good film forming properties (Ghanbarzadeh et al., 2011). Carboxymethyl cellulose based film is a very efficient oxygen, carbon dioxide, and lipid barrier. However, it has poor resistance to water vapor transmission (Ghanbarzadeh and Almasi, 2011).

The chemically modified celluloses are degradable only under certain circumstances, as more recalcitrant, hydrophobic ester groups replace the native glucopyranosyl hydroxyls (to varying degrees) in the esterification procedure. Structurally, the degrees of substitution and C-2 hydroxyl substitution patterns are important criteria in predicting biodegradation patterns for these polymers (Amass et al., 1998). Biodegradation rates of cellulose esters generally increase with decreasing degrees of acetate substitution.

\subsection{Fibers (Lignocellolosic complex)}

Plant fibers include bast (or stem or soft sclerenchyma) fibers, leaf or hard fibers, seed, fruit, wood, cereal straw, and other grass fibers. All these plant based natural fibers are lignocellulosic in nature and are composed of cellulose, hemicelluloses, lignin, pectin and waxy substances (Kabir et al., 2012). Lignocellulosic biomass comprises approximately $50 \%$ of the global biomass and is by far the most abundant renewable organic resource on earth. This woody material is comprised of $30-50 \%$ cellulose, $20-50 \%$ hemicellulose, and $15-35 \%$ lignin, dependent upon the plant species and environmental (growing) conditions (Galbe and Zacchi, 2002). Fig. 5 presents the model of the structural organization of the three major structural constituents of the fiber cell wall (Madsen, 2004). Hemicellulose molecules are hydrogen bonded with cellulose fibrils and they form cementing materials for the fiber structure. Lignin and pectin are coupled with the cellulose-hemicellulose network and provides an adhesive quality to hold the molecules together. This adhesive quality is the cause for the strength and stiffness properties of the fiber.

Hemicellulose is not a form of cellulose and the name is a misnomer. They comprise a group of polysaccharides composed of a combination of 5- and 6-carbon ring sugars (Fig. 6a). Hemicellulose differs from cellulose in three aspects. Firstly, they contain several different sugar units whereas cellulose contains only 1,4- $\beta$-D-glucopyranose units. Secondly, they exhibit a considerable degree of chain branching containing pendant side groups giving rise 
to its non crystalline nature, whereas cellulose is a linear polymer. Thirdly, the degree of polymerization of native cellulose is 10-100 times higher than that of hemicelluloses (John and Thomas, 2008). The degree of polymerization (DP) of hemicellulose is around 50-300. Hemicellulose is very hydrophilic, soluble in alkali and easily hydrolyzed in acids.

Lignin is a complex hydrocarbon polymer with both aliphatic and aromatic constituents (Fig. $6 b)$. They are totally insoluble in most solvents and cannot be broken down to monomeric units. Lignin is totally amorphous and hydrophobic in nature. It is the compound that gives rigidity to the plants. It is thought to be a complex, three-dimensional copolymer of aliphatic and aromatic constituents with very high molecular weight. Hydroxyl, methoxyl and carbonyl groups have been identified. Lignin has been found to contain five hydroxyl and five methoxyl groups per building unit. It is believed that the structural units of lignin molecule are derivatives of 4-hydroxy-3-methoxy phenylpropane (John and Thomas, 2008). The main difficulty in lignin chemistry is that no method has been established by which it is possible to isolate lignin in its native state from the fiber. Lignin is considered to be a thermoplastic polymer exhibiting a glass transition temperature of around $90{ }^{\circ} \mathrm{C}$ and melting temperature of around $170{ }^{\circ} \mathrm{C}$ (Olesen and Plackett, 1999). It is not hydrolyzed by acids, but soluble in hot alkali, readily oxidized, and easily condensable with phenol.

Pectins are a collective name for heteropolysaccarides. They give plants flexibility. Pectin, is a complex anionic polysaccharide composed of $\beta$-1,4-linked D-galacturonic acid residues, where in the uronic acid carboxyls are either fully (HMP, high methoxy pectin) or partially (LMP, low methoxy pectin) methyl esterified (Tharanathan, 2003) (Fig. 6c).

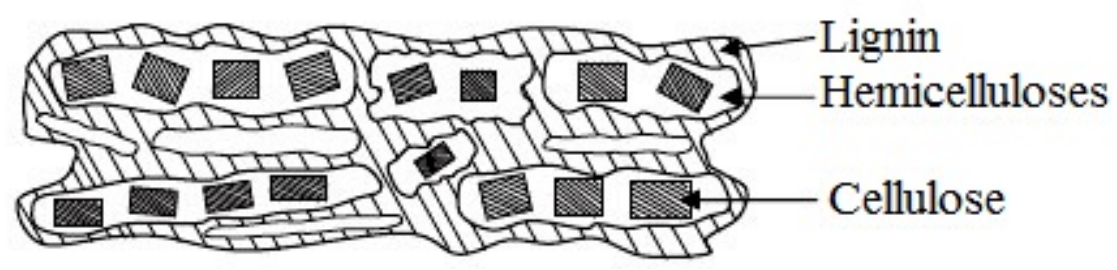

Figure 5. Structural organization of the three major constituents in the fiber cell wall (Kabir et al., 2012).

It has been proposed various techniques for separation of these components from lignocellulosic complex. The 'Clean Fractionation Process', developed and patented by the National Renewable Energy Laboratory (Golden, CO, USA), is one example of an organic solvent-based system used to separate and purify the three major feedstocks present in lignocellulosic biomass (Smith, 2005). Lignin and hemicellulose are disrupted and solubilized in the solvent mixture composed of water, methyl-isobutyl-ketone (MIBK), ethanol, and sulfuric acid $\left(\mathrm{H}_{2} \mathrm{SO}_{4}\right)$, following a steam explosion treatment catalyzed by the acidic conditions created within the reactor due to the added sulfuric acid and endogenous acetic acid released during the hydrolysis. This environmentally benign process selectively separates cellulose, hemicel- 
lulose, and lignin with a high degree of purity, substantial energy savings, and lessened production cost (Kulesa, 1999).

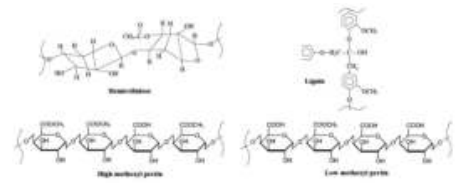

Figure 6. Chemical structure of hemicelluloses, lignin and pectins (Kabir et al., 2012; Tharanathan, 2003).

These lignocellulosic materials have the potential to be utilized as a feedstock for the production of a wide variety of industrial and commodity products, ranging from paper, lumber, and platform chemicals to a variety of fuels and advanced materials, including biodegradable polymers (Smith, 2005). For example, HMP forms excellent films. Plasticized blends of citrus pectin and high amylase starch give strong, flexible films, which are thermally stable up to $180^{\circ} \mathrm{C}$. Pectin is also miscible with poly(vinyl alcohol) in all proportions. Potential commercial uses for such films are water soluble pouches for detergents and insecticides, flushable liners and bags, and medical delivery systems and devices (Tharanathan, 2003).

Hemicellulose can be utilized in microbial fermentations for the production of a variety of value-added products. Detoxified hemicellulosic hydrolysates have been used as xylose-rich feedstocks in a variety of biotechnological applications including the microbial production of ethanol, xylitol, and biodegradable polyhydroxyalkanoate (PHA) polymers (Smith, 2005). Production of PHAs based on renewable, bio-based substrates could make PHA-derived thermoplastic products more economically competitive with petroleum-based plastics, as the major costs in PHA production are the carbon source and the separation process. In the next section of this chapter we will describe the properties of this family of degradable microbial polyesters.

\subsection{Chitin and chitosan}

Chitin is a polysaccharide found in the shells of crabs, lobsters, shrimps and insects or can be generated via fungal fermentation processes. Chitosan is the deacylated derivative of chitin and forms the exoskeleton of arthropod. Structurally chitosan is a linear polysaccharide consisting of $\beta$ (1-4) linked D-glucosamine with randomly located $N$-acetylglucosamine groups depending upon the degree of deacetylation of the polymer (Nair and Laurencin, 2007). Fig. 7 shows the structure of chitin and chitosan.

Chitin is insoluble in its native form but chitosan, is water soluble. Chitosan is soluble in weekly acidic solutions resulting in the formation of a cationic polymer with a high charge density and can therefore form polyelectrolyte complexes with wide range of anionic polymers (Pachence et al., 2007). Chitosan has been found to be non-toxic after oral administration in humans and is an FDA approved food additive (Nair and Laurencin, 2007). 
Enzymes, such as chitosanase, lysozyme and papain are known to degrade chitosan in vitro. The in vivo degradation of chitosan is primarily due to lysozyme and takes place through the hydrolysis of the acetylated residues. The rate of degradation of chitosan inversely depends on the degree of acetylation and crystallinity of the polymer (Shi et al., 2006). The highly deacetylated form exhibits the lowest degradation rates and may last several months in vivo. Apart from this, chemical modification of chitosan can significantly affect its solubility and degradation rate. Chemical modification of chitosan produces materials with a variety of physical and mechanical properties.

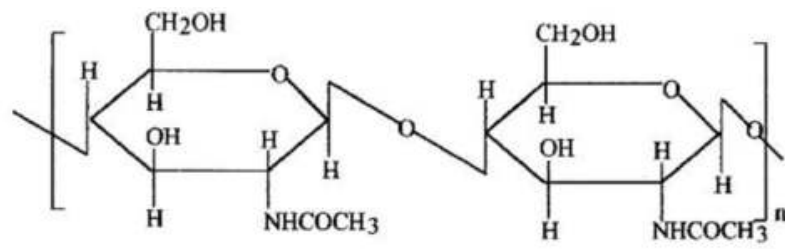

Chitin

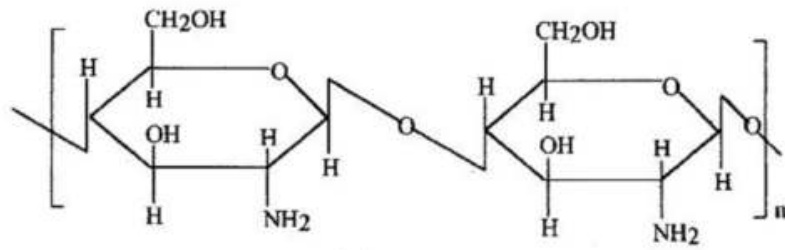

Chitosan

Figure 7. Chemical structure of chitin and chitosan (Nair and Laurencin, 2007).

These biopolymers are biocompatible and have antimicrobial activities as well as the ability to absorb heavy metal ions. They also find applications in the cosmetic industry because of their water-retaining and moisturizing properties (Chandra and Rustgi, 1998). Chitosan has been formed into membranes and matrices suitable for several tissue-engineering applications (Shalaby et al., 2004). Chitin derivatives can also be used as drug carriers. Chitosan was used to develop injectable thermo-sensitive carrier material for biomedical applications. Due to the mild gelling conditions, the hydrogel has been found to be a potential delivery vehicle for growth factors, small molecular weight drugs and cells for localized therapy (Nair et al., 2006). The high chemical reactivity of chitosan, has also led to several chitosan-drug conjugates for cancer therapy (Onishi et al., 2001). Chitosan gels, powders, films, and fibers have been formed and tested for many applications such as encapsulation, membrane barriers, contact lens materials, cell culture, and inhibitors of blood coagulations (Pachence et al., 2007). Chitosan has good film forming properties and therefore can be used as a food packaging material (Ghanbarzadeh et al., 2008; Suyatama et al., 2005). 


\subsection{Gums}

Gums are a group of polysaccharides that can form gels in solution upon the introduction of counterions. The degree of cross-linking is dependent on various factors such as $\mathrm{pH}$, type of counterion, and the functional charge density of these polymers (Chandra and Rustgi, 1998). The common types of these polysaccharides will be discussed here.

Alginic acid present within the cell walls and intercellular spaces of brown algae and has a structural role in giving flexibility and strength to marine plants. Alginate is a non-branched, binary copolymer of (1-4) glycosidically linked $\beta$-D-mannuronic acid and $\alpha$-L-guluronic acid monomers. The composition of alginate (the ratio of the two uronic acids and their sequential arrangements) varies with the source (Nair and Laurencin, 2007). Alginates are extracted from the algae using a base solution and then reacted with acid to form alginic acid. They are high molecular weight polymers having molecular weights up to $500 \mathrm{kDa}$ (Augst et al., 2006). Alginic acid forms water-soluble salts with monovalent cations, low molecular weight amines, and quaternary ammonium compounds. Due to its non-toxicity, alginate has been extensively used as a food additive and a thickener in salad dressings and ice creams (Nair and Laurencin, 2007). Alginate gels have been used widely in controlled release drug delivery systems. Alginates have been used to encapsulate various herbicides, microorganisms and cells. Even though alginates have been extensively investigated as biomaterials, one of the main disadvantages of using alginate-based materials is their inability to undergo enzymatic degradation by mammals (Bouhadir et al., 2001).

\subsubsection{Polypeptides (Proteins)}

Proteins can be defined as natural polymers able to form amorphous three-dimensional structures stabilized mainly by noncovalent interactions. The functional properties of these materials are highly dependent on structural heterogeneity, thermal sensitivity, and hydrophilic behavior of proteins. Numerous vegetable and animal proteins are commonly used as biodegradable polymers.

\subsection{Corn zein}

Zein comprises a group of alcohol-soluble proteins (prolamins) found in corn endosperm. It accounts for $50 \%$ or more of total endosperm protein, and its only known role is the storage of nitrogen for the germinating embryo (Gennadios, 2002). It can be extracted with aqueous alcohol and dried to a granular powder. Based on solubility differences, zein consists of three protein fractions, i.e., $\alpha$-zein, $\beta$-zein, and $\gamma$-zein. $\alpha$-Zein accounts for 75 to $85 \%$ of the total protein and is dominated by two groups of proteins, Z19 and Z22, according to sodium dodecyl sulfate-polyacrylamide gel electrophoresis (SDS PAGE) (Argos et al., 1982). Z19 and Z22 consist of 210 and 245 amino acids, respectively.

Due to the hydrophobic nature of zein, water sorption is extremely low in the low water activity $\left(a_{w}\right)$ range. Water sorption, though, increased exponentially with $a_{w}$ (Watt, 1983). Zein, although not soluble in water, is readily plasticized by it. Zein films are brittle at ambient temperature and need plasticization to become flexible. Plasticization increases polymer 
mobility, decreases glass transition temperature $\left(\mathrm{T}_{\mathrm{g}}\right)$, and markedly changes rheological properties (Ghanbarzadeh, et al., 2006a; 2006b; 2007a). Common zein plasticizers include glycerol, glyceryl monoesters, poly ethylene glycol, and fatty acids.

The film-forming properties of zein have been recognized for decades, and they are the basis for its commercial utilization (Lai et al., 1997). Coating films are formed on hard surfaces by covering them with zein solutions and allowing the solvent to evaporate off. The dried zein residue forms hard and glossy, scuff-proof, protective coatings that also are resistant to microbial attack (Reiners et al., 1973). Zein coatings are used as oxygen, lipid, and moisture barriers for nuts, candies, confectionery products, and other foods. Rice fortified with vitamins and minerals has been coated with zein/stearic acid/wood resin mixtures to prevent vitamin and mineral losses during washing in cold water. Pharmaceutical tablets are zein-coated for controlled ingredient release and protection (Gennadios, 2002). Use of zein-based coatings has been suggested for reducing oil uptake by deep-fat fried foods, for protecting active ingredients in chewing gum, for achieving controlled release of active ingredients in pharmaceutical tablets and for masking the taste of orally administered drugs (Gennadios, 2002). Zein, upon casting from aqueous aliphatic alcoholic solutions forms tough, glossy and grease resistant films (Ghanbarzadeh et al., 2006c; 2007b). By cross-linking the tensile strength of the films is further improved. Zein films have water vapor permeability (WVP) values lower than or similar to those of other protein films, cellulose ethers, and cellophane (Krochta, 1992). However, their WVP is notably higher than that of LDPE or ethylene-vinyl alcohol copolymer (EVOH) (Gennadios, 2002).

\subsection{Wheat gluten}

Whereas dry wheat flour comprises $9-13 \%$ protein and $75-80 \%$ starch, wheat gluten consists mainly of wheat storage protein (70-80\%, dry matter basis) with traces of starch and non starch polysaccharides (10-14\%), lipids (6-8\%), and minerals (0.8-1.4\%). Osborne distinguished four wheat protein classes based on their solubility in different solvents, namely, albumins, globulins, gliadins, and glutenins. The albumins and globulins (15-22\% of total protein), which are, respectively, water- and salt-soluble, are removed with starch granules during gluten processing. In contrast, the gliadins, which are alcohol-soluble, and the glutenins, which are soluble (or at least dispersible) in dilute acid or alkali solutions, are being collected into gluten (Wrigley and Bietz, 1988). Gliadin molecules may interact together or with glutenin molecules via hydrophobic interactions and hydrogen bonds. In the fully hydrated state, gliadin exhibits viscous flow properties without significant elasticity. For cereal technologists, gliadin accounts for the extensibility of wheat flour dough and acts as a filler diluting glutenin interactions. Contrary to gliadin, which is comprised of distinct polypeptide chains, glutenin consists of polymers made from polypeptide chains (also named subunits) linked end-to-tail by SS bonds (Kasarda, 1999). Vital wheat gluten is the cohesive and elastic mass that is leftover after starch is washed away from wheat flour dough. Commercially, it is an industrial by-product of wheat starch production via wet milling (Gennadios, 2002).

Wheat gluten is suitable for numerous food and nonfood uses. Its main application is in the bakery industry, where it is used to strengthen weak flours rendering them suitable for bread 
baking (Gennadios, 2002). The other potential applications of gluten are very diverse: windows in envelopes, surface coatings on paper, biodegradable plastic films for agricultural uses, water-soluble bags with fertilizers, detergents, cosmetics, cigarette filters and additives and molded objects (Cuq et al., 1998). Wheat gluten-based materials are homogeneous, transparent, mechanically strong, and relatively water resistant. They are biodegradable and a priori biocompatible, apart from some wheat gluten-specific characteristics such as allergenicity (Guilbert et al., 1996).

The moisture barrier properties of wheat gluten-based films are relatively poor as compared to synthetic films, such as LDPE. The gas $\left(\mathrm{O}_{2}, \mathrm{CO}_{2}\right.$, and ethylene) barrier properties of wheat gluten-based films are highly interesting, as they are exceptionally good at low relative humidity $(\mathrm{RH})$ conditions. Water and other plasticizers can lower the glass transition temperature $\left(\mathrm{T}_{\mathrm{g}}\right)$ of the wheat gluten and enable processing at temperatures below those that lead to protein decomposition, which means that protein-based films can be formed by using techniques that are conventionally used with synthetic polymers (e.g., extrusion, injection, and molding) (Gennadios, 2002).

\subsection{Soy protein}

The major use of soybean in the food industry is as a source of oil, while soy protein concentrate and isolate are readily available as co-products of the oil processing industry (Pszczola, 1998). Soy protein is a complex mixture of proteins with widely different molecular properties. The major soybean proteins have molecular weights ranging from 200 to $600 \mathrm{kDa}$. Most soy proteins ( $90 \%)$ are globulins, which can be fractionated into $2 \mathrm{~S}, 7 \mathrm{~S}, 11 \mathrm{~S}$ and $15 \mathrm{~S}$ according to their sedimentation coefficients. The 7S and11S fractions, the main fractions making up about $37 \%$ and $31 \%$ of the total extractable protein, have the capability of polymerization (Wolf, 1972). Soy protein used in the food industry is classified as soy flour, concentrate, or isolate based on the protein content. Soy flour contains $50-59 \%$ protein and is obtained by grinding defatted soy flakes. Soy protein concentrate contains $65-72 \%$ protein and is obtained by aqueous liquid extraction or acid leaching process. Soy protein isolate contains more than $90 \%$ protein and is obtained by aqueous or mild alkali extraction followed by isoelectric precipitation (Soy Protein Council, 1987).

Soy protein is an abundant and relatively cheap ingredient source for various food applications. The functional properties that make soy protein useful in foods include cohesiveness, adhesiveness, emulsification, dough and fiber formation, whippability, solubility, and foaming (Gennadios, 2002). Soy protein also is used in infant formulas and in baked, meat, and dairy products (Witherly, 1990). The use of soy protein as a film-forming agent can add value to soybeans by creating new channels for marketing soy proteins (Cao et al., 2007). Soy protein is a viable and renewable resource for producing edible and environmentally friendly biodegradable films. Soy protein films are flexible, smooth, transparent, and clear compared to other films from plant proteins (Cho and Rhee, 2004). These films have good mechanical properties but they are generally slightly water-resistant (Cuq et al., 1998). Soy protein films are typically prepared by drying thin layers of cast film-forming solutions (Gennadios, 2002). 
Biodegradable plastics were also produced from soy isolate and concentrate by a thermomolding process (Jane et al., 1994).

\subsection{Collagen and gelatin}

Collagen is an abundant protein constituent of connective tissue in vertebrate (about $50 \%$ of total human protein) and invertebrate animals. Similar to cellulose in plants, collagen molecules support mechanical stresses transferred to them by a low-modulus matrix (Gennadios, 2002). Collagen is a rod-type polymer nearly $300 \mathrm{~nm}$ long with a molecular weight of 300,000. There have been more than twenty two different types of collagen identified so far in the human body, with the most common being Type I-IV. Type I collagen is the single most abundant protein present in mammals and is the most thoroughly studied protein. The Type I collagen is composed of three polypeptide subunits with similar amino acid compositions. Each polypeptide is composed of about 1050 amino acids, containing approximately $33 \%$ glycine, $25 \%$ proline and 25\% hydroxyproline with a relative abundance of lysine (Nair and Laurencin, 2007). Collagen is a hydrophilic protein because of the greater content of acidic, basic, and hydroxylated amino acid residues than lipophilic residues. Therefore, it swells in polar liquids with high solubility parameters.

Collagen undergoes enzymatic degradation within the body via enzymes, such as collagenases and metalloproteinases, to yield the corresponding amino acids. Due to their enzymatic degradability, unique physico-chemical, mechanical and biological properties collagen has been extensively investigated for various applications. Collagen is mostly soluble in acidic aqueous solutions and can be processed into different forms such as sheets, tubes, sponges, foams, nanofibrous matrices, powders, fleeces, injectable viscous solutions and dispersions. Studies have also shown that the degradation rate of collagen used for biomedical applications can be significantly altered by enzymatic pre-treatment or cross-linking using various crosslinking agents (Nair and Laurencin, 2007).

Type I collagen is found in high concentrations in tendon, skin, bone, and fascia, which are consequently convenient and abundant sources for isolation of this natural polymer. The major sources of collagen currently used for industrial applications are bovine or porcine skin or bovine or equine Achilles tendons (Pachence et al., 2007). Thermal or chemical dissociation of collagen polypeptide chains forms products known as gelatin. Insoluble collagen is converted to soluble gelatin by acid or alkaline/lime (mild and slow) processing. Two processes are mainly used for commercial production of gelatin. In the first process, the collagen in hide or demineralized bone is partly depolymerized by prolonged liming that breaks down covalent cross-links. The occurring hydrolysis results in extensive release of collagenous material, which is solubilized at near neutral $\mathrm{pH}$ at temperatures of $60-90{ }^{\circ} \mathrm{C}$ (Type B gelatin). The acid process (Type A gelatin) involves soaking skin or bone in a dilute acid followed by extraction at acid $\mathrm{pH}$ (Johnston-Banks, 1990).

The properties of collagen and gelatin are of great interest to various fields, such as surgery (implantations; wound dressings), leather chemistry (tanning), pharmacy (capsule production; tablet binding), and food science (gels; edible films) (Arvanitoyannis et al., 1998). Reportedly, about $65 \%$ of gelatin manufactured worldwide is used in foods, $20 \%$ in photo- 
graphic applications, $10 \%$ in pharmaceutical products, and $5 \%$ in other specialized and industrial applications (Slade and Levine, 1987). Collagen has been extensively investigated for the localized delivery of low molecular weight drugs including antibiotics (Gruessner et al., 2001). Collagen films have traditionally been used for preparing edible sausage casing (Hood, 1987). Gelatin has been successfully used to form films that are transparent, flexible, water-resistant, and impermeable to oxygen (Hebert and Holloway 1992). These films were made by cooling and drying an aqueous film-forming solution based on gelatin. Gelatin is also used as a raw material for photographic films, and to microencapsulate aromas, vitamins, and sweeteners (Balassa and Fanger 1971).

\subsection{Casein and caseinates}

Casein is the main protein of milk, representing $80 \%$ of the total milk proteins, it is a phosphoprotein that may be separated into various electrophoretic fractions, $\alpha_{\mathrm{s} 1}$-casein, $\alpha_{\mathrm{s} 2}$-casein, $\beta$-casein and $\kappa$-casein which differ in primary, secondary and tertiary structure and molecular weight. These four different types of casein are found in bovine milk in the approximate ratio of 4:1:4:1 respectively (Dalgleish, 1997). Casein exists in the form of micelles containing all four casein species complexed with colloidal calcium phosphate. The casein micelles are stable to most common milk processes such as heating, compacting, and homogenization. Micellar integrity is preserved by extensive electrostatic and hydrogen bonding, and hydrophobic interactions (Gennadios, 2002).

Two principal methods have been established for the production of casein on commercial scale, i.e., isoelectric precipitation (acid casein) and enzymatic coagulation (rennet casein). The preparation of acid casein from skim milk is quite simple. The essential steps involve acidification to about $\mathrm{pH} 4.6$ (isoelectric point of casein) to induce the coagulation of casein, adjustment of temperature to between 30 and $40{ }^{\circ} \mathrm{C}$ for better handling properties of the product, washing, pressing or centrifuging the curd to remove excessive water, and finally drying and grinding. Hydrochloric acid is usually used for both laboratory scale and industrial preparation of casein. The key difference in producing rennet casein from producing acid casein is the means of coagulation. A proteolytic enzyme, such as chymosin (rennin), cleaves the -casein fraction to release a glycomacropeptide, thus destabilizing the casein micelles and promoting coagulation of casein in the presence of calcium cations (Gennadios, 2002). Though waterinsoluble casein has some applications, most food application would require casein with high water solubility. This is achieved by dispersing the casein in water and adjusting the $\mathrm{pH}$ to between 6.5 and 7.0 with an alkali. The most commonly used soluble caseinate is sodium caseinate. It is normally manufactured by dissolving fresh acid casein curd in sodium hydroxide followed by spray drying. Other soluble caseinates prepared in a similar manner include potassium, calcium, magnesium, and ammonium caseinates (Fox and McSweeney, 1998).

Its relative simple isolation and the useful properties of casein as an industrial material and food ingredient have led to commercial production of casein and caseinates since the 19th century (Muller, 1982). Casein and caseinates are suitable for numerous food and nonfood uses such as in industrial applications (especially in glues, paper coatings, paints, leather finishing, textile fibers, and plastics), and in various food products. The end-uses of casein and caseinates 
have gradually shifted from industrial to food applications. About 70 to $80 \%$ of the casein produced worldwide is used as a food ingredient (Gennadios, 2002). Film-forming properties of caseins have been used to improve the appearance of numerous foods, to produce watersoluble bags, and to produce origin or quality identification labels inserted under precut cheeses, to ensure the surface retention of additives on intermediate-moisture foods, and to encapsulate polyunsaturated lipids for animal feeds (Cuq et al., 1998). Casein-based edible films are attractive for food applications due to their high nutritional quality, excellent sensory properties and potential to adequately protect food products from their surrounding environment (Fabra et al., 2009). The mechanical properties of casein and caseinate films, being neither too tough nor too fragile, also make them suitable for edible purposes. Though more permeable to water vapor than plastic films, they are capable of retarding moisture transfer to some degree (Buonocore et al., 2003). Casein and caseinate films dissolve nearly instantaneously in water and this is desirable for many food applications.

\subsection{Whey proteins}

Whey proteins are those proteins that remain in milk serum after $\mathrm{pH} /$ rennet coagulation of casein during cheese or casein manufacture (Gennadios, 2002). Whey protein, which represents approximately $20 \%$ of total milk proteins is a mixture of proteins with diverse functional properties. The five main proteins are $\alpha$-lactalbumins, $\beta$-lactoglobulins, bovine serum albumin, immunoglobulins, and proteose peptones. $\alpha$-lactalbumins, $\beta$-lactoglobulins and bovine serum albumin comprise 57,19 and $7 \%$ of the total whey protein. The immunoglobulins and proteose-peptone fractions represent the remainder of the whey protein. Whey proteins are globular and soluble at pH 4.6 (Dybing and Smith, 1991).

The industrial processes used for whey protein recovery are ultrafiltration, reverse osmosis, gel filtration, electrodialysis, and ion exchange chromatography. Fractionated whey constituents of various degrees of concentration can be obtained by combining two or more of the above recovery processes (Sienkiewicz and Riedel, 1990). Whey protein products can be classified according to their composition. In particular, they are divided according to their protein content. Whey protein concentrate (WPC) contains $25-80 \%$ protein. Whey protein isolate (WPI) is nearly all protein (>90\%) (Gennadios, 2002).

Whey protein, a byproduct of the cheese industry, has excellent nutritional and functional properties and the potential to be used for human food and animal feed. The film-forming properties of whey proteins have been used to produce transparent, flexible, colorless, and odorless films, such as those produced from caseins (Cuq et al., 1998). The use of whey proteins to make an edible packaging film material brings several environmental advantages because of the film's biodegradability and its capacity to control moisture, carbon dioxide, oxygen, lipid, flavor and aroma transfer (Ozdemir and Floros, 2008). These properties offer the potential to extend the shelf-life of many food products, avoiding quality deterioration (Gounga et al., 2007). 


\subsection{Other proteins}

Prevalent types of plant and animal proteinous biopolymers have been discussed previously. Nevertheless, these are not the only available biopolymers from this category. There are other proteins, which have potential to use as biopolymeric materials for different applications. Most important of them includes elastin (a major protein component of vascular and lung tissue), egg albumins, fish myofibrillar protein and wool keratin (Gennadios, 2002).

An interesting property of elastin is its ability to undergo folding when the temperature is increased above $25{ }^{\circ} \mathrm{C}$. This is due to its transition from a disordered form to an ordered form at higher temperature called inverse temperature transition (ITT). Due to the unique thermal transition properties of elastin, it has been extensively investigated as a smart, injectable drug delivery system (Mithieux et al., 2004). Use of egg albumins to encapsulate organic hydrophobic compounds in cosmetics and foods has been proposed in many patents (Gennadios et al., 1999). The potential use of myofibrillar proteins for the preparation of films and coatings was proposed to identify new practical applications for fish proteins (Shiku et al., 2004). Yamauchi et al (1996) developed water-insoluble films based on keratin by casting and drying alkaline dispersions. The large amount of cystine in keratin favors formation of many disulfide bonds that could stabilize the proteic network. However, because of their unpleasant mouthfeel, edible coatings based on keratin have not found many applications (Yamauchi and Khoda, 1997).

Other proteins have been also used for various purposes, including proteins from rye, pea, barley, sorghum, rice, sunflower, pistachio and peanut (Gennadios, 2002).

\subsubsection{Biopolymers produced directly by natural or genetically modified organisms}

\subsubsection{Microbial polyesters}

The microbial polyesters are produced by biosynthetic function of a microorganism and readily biodegraded by microorganisms and within the body of higher animals, including humans. In the field of medicine, they can be used as implanting material and a drug carriers.

\subsection{Polyhydroxyalcanoates (PHAs)}

Polyhydroxyalkanoates (PHAs) are a family of intracellular biopolymers synthesized by many bacteria as intracellular carbon and energy storage granules (Fig. 8). Depending on growth conditions, bacterial strain, and carbon source, the molecular weights of these polyesters can range from tens into the hundreds of thousands (Pachence et al., 2007). Bacterially synthesized PHAs have attracted attention because they can be produced from a variety of renewable resources and are truly biodegradable and highly biocompatible thermoplastic materials.

The plastic-like properties and biodegradability of PHAs offer an attraction as a potential replacement for non-degradable polyethylene and polypropylene. Many efforts have been made to produce PHA as environmentally degradable thermoplastics (Chen et al., 2001; Chen and Page, 1997; Byrom, 1992). PHAs have a promising potential for food packaging applications. However, due to exorbitant production costs, few suppliers exist in the market. 
Over 90 different types of PHA consisting of various monomers have been reported and the number is increasing. Some PHAs behave similarly to conventional plastics such as polyethylene and polypropylene, while others are elastomeric (Yang et al., 2002). The most representative member of this family is poly(3-hydroxybutyrate) (PHB).

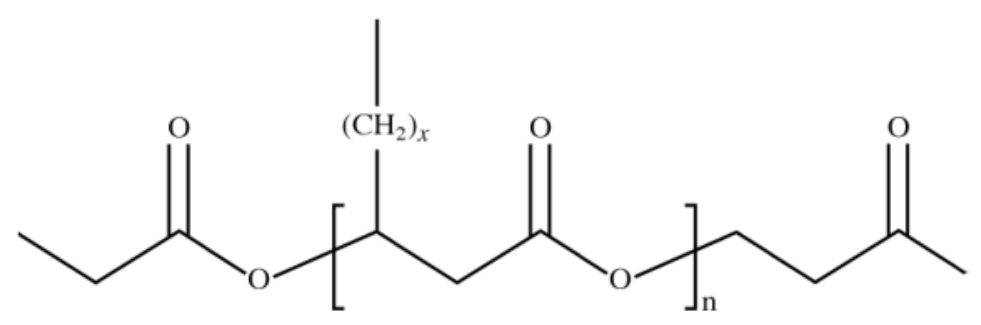

Figure 8. Chemical structure of polyhydroxyalkanoate ( Pachence et al., 2007).

\subsection{Poly-3-hydroxybutyrate (PHB)}

Among the PHA family, poly-3-hydroxybutyrate (PHB) is the most common member; it belongs to the short chain length PHA with its monomers containing 4-5 carbon atoms (Smith, 2005). ICI developed a biosynthetic process for the manufacture of PHB, based on the fermentation of sugars by the bacterium Alcaligenes eutrophus. PHB homopolymer, like all other PHA homopolymers, is highly crystalline, extremely brittle, and relatively hydrophobic. Consequently, the PHA homopolymers have degradation times in vivo on the order of years (Holland et al., 1987; Miller and Williams, 1987).

PHB has the poorest mechanical properties compared with its copolymers. Efforts have been made to improve the mechanical properties of PHB; Iwata et al. (2003) prepared uniaxially oriented films of PHB, with sufficient strength and flexibility by cold-drawing from an amorphous preform at a temperature below, but near to, the glass transition temperature. Melt crystallized and solvent-cast films of PHB are usually quite brittle, and the orientation is critical and difficult to reproduce consistently.

Since current production technology is still unable to produce any PHB that is competitive with conventional plastics such as polyethylene, polypropylene or polystyrene which are manufactured on a large scale, the application of PHB as environmentally friendly packaging materials is still unrealistic. Therefore, increasing research is focused on the biosynthesis of PHB with unconventional structures that may bring new properties and new applications for PHB (Eggink et al., 1995; Lutke-Eversloh, et al., 2001; Kim, et al., 1996).

PHB has been found to have low toxicity, in part due to the fact that it degrades in vivo to d3hydroxybutyric acid, a normal constituent of human blood. Applications of these polymers previously tested or now under development include controlled drug release, artificial skin, and heart valves as well as such industrial applications as paramedical disposables (Doi et al., 1990; Sodian et al., 2000). 


\subsection{Poly (Hydroxybutyrate-Hydroxyvalerate) (PHB/HV)}

Blends of the PHB family are usually compatible and co-crystallization is enhanced. Yoshie et al., (2004) studied solid-state structures and crystallization kinetics of poly (3-hydroxybutyrate-co-3-hydroxyvalerate) ( $\mathrm{PHB} / \mathrm{HV}$ ) blends. It was found that $\mathrm{PHB}$ and $\mathrm{HV}$ can co-crystallize.

The copolymers of PHB with hydroxyvaleric acid (PHB/HV) (Fig. 9) are less crystalline, more flexible, and more readily processible, but they suffer from the same disadvantage of being too hydrolytically stable to be useful in short-term applications when resorption of the degradable polymer within less than one year is desirable.

PHB and its copolymers with up to 30\% of 3-hydroxyvaleric acid are now commercially available under the trade name Biopol. It was found previously that a PHA copolymer of PHB/ HV with a 3- hydroxyvalerate content of about $11 \%$, may have an optimum balance of strength and toughness for a wide range of possible applications (Pachence et al., 2007).

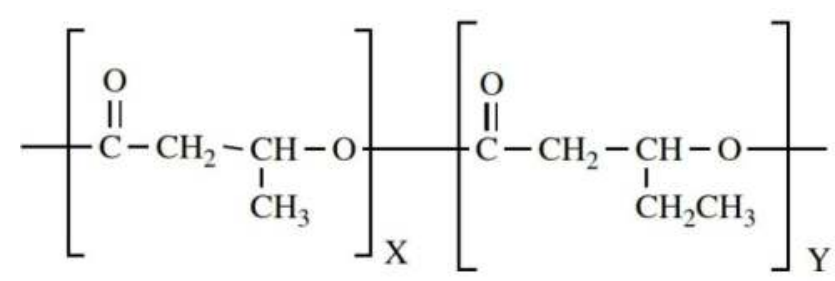

hydroxybutyric acid (HB) hydroxyvaleric acid (HV)

Figure 9. Poly(b-hyroxybutyrate) and copolymers with hydroxyvaleric acid. For a homopolymer of HB, $\mathrm{Y}=0$; commonly used copolymer ratios are 7, 11, or 22 mole percent of hydroxyvaleric acid. (Pachence et al., 2007)

\subsection{Poly- $\varepsilon$-Caprolactones (PCL)}

Poly ( $\varepsilon$-caprolactone) (PCL) (Fig. 10) is aliphatic polyester and is of great interest as it can be obtained by the ring opening polymerization of a relatively cheap monomeric unit ' $\varepsilon$-caprolactone'. This polyester is highly processible as it is soluble in a wide range of organic solvents (Nair and Laurencin, 2007).

PCL exhibits several unusual properties not found among the other aliphatic polyesters. Most noteworthy are its exceptionally low glass transition temperature of $-62^{\circ} \mathrm{C}$ and its low melting temperature of $57^{\circ} \mathrm{C}$. Another unusual property of PCL is its high thermal stability. Whereas other tested aliphatic polyesters had decomposition temperatures $\left(T_{d}\right)$ between 235 and $255^{\circ} \mathrm{C}$, PCL has a $T_{d}$ of $350^{\circ} \mathrm{C}$ (Pachence et al., 2007). PCL has low tensile strength (approximately $23 \mathrm{MPa}$ ) but an extremely high elongation at breakage (4700\%) (Gunatillake et al., 2006). In addition, $\varepsilon$-caprolactone can be copolymerized with numerous other monomers (e.g., ethylene oxide, chloroprene, THF, $\delta$-valerolactone, 4-vinylanisole, styrene, methyl methacrylate, 
vinylacetate). Particularly noteworthy are copolymers of $\varepsilon$-caprolactone and lactic acid that have been studied extensively (Feng et al., 1983).

PCL undergoes hydrolytic degradation due to the presence of hydrolytically labile aliphatic ester linkages; however, the rate of degradation is rather slow (2-3 years). PCL is a semicrystalline polymer with a low glass transition temperature of about $-60^{\circ} \mathrm{C}$. Thus, PCL is always in a rubbery state at room temperature. Among the more common aliphatic polyesters, this is an unusual property, which undoubtedly contributes to the very high permeability of PCL for many therapeutic drugs (Pitt et al., 1987). Due to the slow degradation, high permeability to many drugs and non-toxicity, PCL was initially investigated as a long-term drug/vaccine delivery vehicle. Extensive research is ongoing to develop various micro- and nano-sized drug delivery vehicles based on PCL (Sinha et al., 2004). Due to its excellent biocompatibility, PCL has also been extensively investigated as scaffolds for tissue engineering.

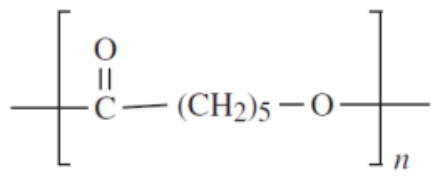

Figure 10. Chemical structure of polyhydroxyalkanoate (Pachence et al., 2007)

\subsubsection{Bacterial Cellulose (BC)}

Bacterial cellulose (BC) belongs to specific products of primary metabolism and is mainly a protective coating, whereas plant cellulose (PC) plays a structural role. Cellulose is synthesized by bacteria belonging to the genera Acetobacter, Rhizobium, Agrobacterium, and Sarcina (Bielecki, 2004). Its most efficient producers are Gram-negative, acetic acid bacteria Acetobacter xylinum (reclassified as Gluconacetobacter xylinus), which have been applied as model microorganisms for basic and applied studies on cellulose (Pamela et al., 1992).

Extensive research on $\mathrm{BC}$ revealed that it is chemically identical to PC, but its macromolecular structure and properties differ from the latter (Fig. 11). Nascent chains of BC aggregate to form subfibrils, which have a width of approximately $1.5 \mathrm{~nm}$ and belong to the thinnest naturally occurring fibers, comparable only to subelemental fibers of cellulose detected in the cambium of some plants and in quinee mucous. BC subfibrils are crystallized into microfibrils, these into bundles, and the latter into ribbons (Bielecki, 2004). Dimensions of the ribbons are 3-4 (thickness) $\times 70-80 \mathrm{~nm}$ (width), whereas the width of cellulose fibers produced by pulping of birch or pine wood is two orders of magnitude larger $\left(1.4-4.0 \times 10^{-2}\right.$ and 3.0-7.5 $\times 10^{-2} \mathrm{~mm}$, respectively) (Iguchi et al., 2000).

$\mathrm{BC}$ is also distinguished from its plant counterpart by a high crystallinity index (above 60\%) and different degree of polymerization (DP), usually between 2000 and 6000, but in some cases reaching even 16,000 or 20,000 , whereas the average DP of plant polymer varies from 13,000 to 14,000 (Iguchi et al., 2000). 
One of the most important features of BC is its chemical purity, which distinguishes this cellulose from that from plants, usually associated with hemicelluloses and lignin, removal of which is inherently difficult (Bielecki, 2004). Because of the unique properties, resulting from the ultrafine reticulated structure, $\mathrm{BC}$ has found a multitude of applications in paper, textile, and food industries, and as a biomaterial in cosmetics and medicine (Hu et al., 2011). Wider application of this polysaccharide is obviously dependent on the scale of production and its cost. Therefore, basic studies run together with intensive research on strain improvement and production process development.
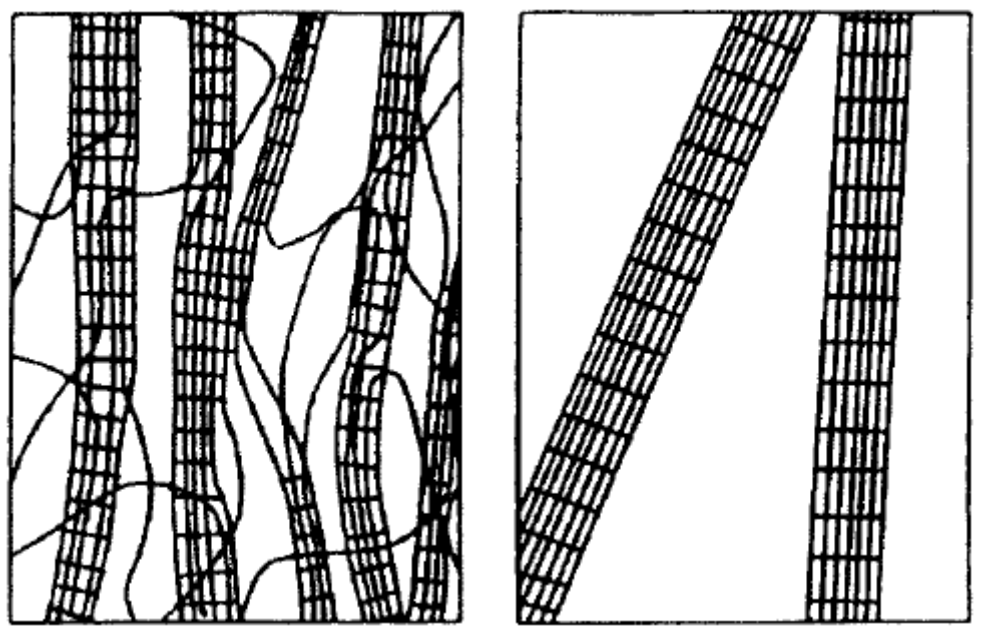

Figure 11. Schematic model of BC microfibrils (Right) drawn in comparison with the 'fringed micelles'; of PC fibrils (Left)(Iguchi et al.,2000)

\subsubsection{Biopolymers (Polyesters) synthesized from bio-derived monomers}

This category of biopolymers belongs to biodegradable polyesters and produced by polycondensation or ring-opening polymerization of biologically derived monomers.

\subsection{Polylactic Acid or polylactide (PLA)}

Among the family of biodegradable polyesters, polylactides (i.e. PLA) have been the focus of much attention because they are produced from renewable resources such as starch, they are biodegradable and compostable, and they have very low or no toxicity and high mechanical performance, comparable to those of commercial polymers (Yu et al., 2006).

PLA or poly-lactide was discovered in 1932 by Carothers. He was only able to produce a low molecular weight PLA by heating lactic acid under vacuum while removing the condensed water. The problem at that time was to increase the molecular weight of the products; and, finally, by ring-opening polymerization of the lactide, high-molecular weight PLA was 
synthesized (Jamshidian et al., 2010). PLA was 1st used in combination with polyglycolic acid (PGA) as suture material and sold under the name Vicryl in the U.S.A. in 1974 (Mehta et al., 2005).

Lactic acid (2-hydroxy propionic acid), the single monomer of PLA (Fig. 12), is produced via fermentation or chemical synthesis. Its 2 optically active configurations, the $\mathrm{L}(+)$ and $\mathrm{D}(-)$ stereoisomers are produced by bacterial (homofermentative and heterofermentative) fermentation of carbohydrates. The homofermentative method is preferably used for industrial production because its pathways lead to greater yields of lactic acid and to lower levels of byproducts. The general process consists of using species of the Lactobacillus genus such as Lactobacillus delbrueckii, L. amylophilus, L. bulgaricus, and L. leichmanii, a $\mathrm{pH}$ range of 5.4 to 6.4, a temperature range of 38 to $42{ }^{\circ} \mathrm{C}$, and a low oxygen concentration. Generally, pure L-lactic acid is used for PLA production (Mehta et al., 2005).

The polymerization of racemic (D,L)-lactide and mesolactide, results in the formation of amorphous polymers. Among these monomers, L-lactide is the naturally occurring isomer. Similar to polyglycolide, poly(L-lactide) (PLLA) is also a crystalline polymer $(\sim 37 \%$ crystallinity) and the degree of crystallinity depends on the molecular weight and polymer processing parameters. It has a glass transition temperature of $60-65^{\circ} \mathrm{C}$ and a melting temperature of approximately $175^{\circ} \mathrm{C}$ (Nair et al., 2007).

Poly (L-lactide) is a slow-degrading polymer compared to polyglycolide, has good tensile strength, low extension and a high modulus (approximately $4.8 \mathrm{GPa}$ ) and hence, has been considered an ideal biomaterial for load bearing applications, such as orthopaedic fixation devices. It is classified as generally recognized as safe (GRAS) by the United State Food and Drug Administration (FDA) and is safe for all food packaging applications (Madhavan Nampoothiri et al., 2010; FDA 2002).

Polylactides undergo hydrolytic degradation via the bulk erosion mechanism by the random scission of the ester backbone. It degrades into lactic acid a normal human metabolic byproduct, which is broken down into water and carbon dioxide via the citric acid cycle (Maurus and Kaeding, 2004).

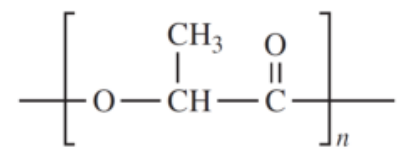

Figure 12. Chemical structure of polylactic acid (Jamshidian et al., 2010)

\subsection{Polyglycolic Acid (PGA)}

Polyglycolide or Polyglycolic acid (PGA) is a biodegradable, thermoplastic polymer and the simplest linear, aliphatic polyester (Fig. 13). 
PGA has been known since 1954 as a tough fiber-forming polymer (Pachence et al., 2007).

Polyglycolide has a glass transition temperature between $35-40{ }^{\circ} \mathrm{C}$ and its melting point is reported to be in the range of $225-230^{\circ} \mathrm{C}$. PGA also exhibits an elevated degree of crystallinity, around $45-55 \%$, thus resulting in insolubility in water. The solubility of this polyester is somewhat unique, in that its high molecular weight form is insoluble in almost all common organic solvents (acetone, dichloromethane, chloroform, ethyl acetate, tetrahydrofuran), while low molecular weight oligomers sufficiently differ in their physical properties to be more soluble. However, polyglycolide is soluble in highly fluorinated solvents like hexafluoroisopropanol (HFIP) and hexafluoroacetone sesquihydrate, that can be used to prepare solutions of the high molecular weight polymer for melt spinning and film preparation. Fibers of PGA exhibit high strength and modulus (7 GPa) and are particularly stiff (Nair et al., 2007).

Polyglycolide is characterized by hydrolytic instability owing to the presence of the ester linkage in its backbone. The degradation process is erosive and appears to take place in two steps during which the polymer is converted back to its monomer glycolic acid: first water diffuses into the amorphous (non-crystalline) regions of the polymer matrix, cleaving the ester bonds; the second step starts after the amorphous regions have been eroded, leaving the crystalline portion of the polymer susceptible to hydrolytic attack. Upon collapse of the crystalline regions the polymer chain dissolves (Tian et al., 2012).

The traditional role of PGA as a biodegradable suture material has led to its evaluation in other biomedical fields. Implantable medical devices have been produced with PGA, including anastomosis rings, pins, rods, plates and screws. It has also been explored for tissue engineering or controlled drug delivery. Tissue engineering scaffolds made with polyglycolide have been produced following different approaches, but generally most of these are obtained through textile technologies in the form of non-woven meshes. The Kureha Corporation has announced its commercialization of high molecular weight polyglycolide for food packaging applications under the trade name of Kuredux®. Production is at Belle, West Virginia, with an intended capacity of 4000 annual metric tons, according to a Chemicals Technology report. Its attributes as a barrier material result from its high degree of crystallization. A low molecular weight version (approximately $600 \mathrm{amu}$ ) is available from the DuPont Co. and is purported to be useful in oil and gas applications (Chandra and Rustgi, 1998).

Owing to its hydrolytic instability, however, its use has initially been limited. Currently polyglycolide and its copolymers (poly(lactic-co-glycolic acid) with lactic acid, poly(glycolideco-caprolactone) with $\varepsilon$-caprolactone, and poly (glycolide-co-trimethylene carbonate) with trimethylene carbonate) are widely used as a material for the synthesis of absorbable sutures and are being evaluated in the biomedical field.

\subsection{Synthetic biodegradable polymers}

\subsubsection{Aliphatic polyesters}

Polyester is a category of polymers which contain the ester functional group in their main chain. Aliphatic polyesters are biodegradable but often lack in good thermal and mechanical 


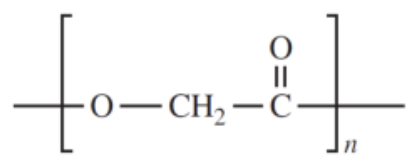

Figure 13. Chemical structure of polyglycolic acid (Pachence et al., 2007)

properties. Vice versa, aromatic polyesters, like Polyethylene terephthalate (PET), have excellent material properties, but are resistant to microbial attack. Among biodegradable polymers, aliphatic polyester-based polymeric structures are receiving special attention because they are all more or less sensitive to hydrolytic degradation, a feature of interest when compared with the fact that living systems function in aqueous media. Only some of these aliphatic polyesters are enzymatically degradable. A smaller number is biodegradable, and an even more limited number is biorecyclable.

\subsubsection{Polyglycolic Acid (PGA), Polylactic Acids (PLA) and their copolymers}

Poly (glycolic acid) (PGA), poly (lactic acid) (PLA), and their copolymers are the most widely used synthetic degradable polymers in medicine. In section 2.1.2.3., structure and properties of these polymers has been explained and in this section synthetic production of them are presented. PGA can be obtained through several different processes starting with different materials (Nair et al., 2007):

1. polycondensation of glycolic acid;

2. ring-opening polymerization of glycolide;

3. solid-state polycondensation of halogenoacetates

Polycondensation of glycolic acid is the simplest process available to prepare PGA, but it is not the most efficient because it yields a low molecular weight product. The most common synthesis used to produce a high molecular weight form of the polymer is ring-opening polymerization of "glycolide", the cyclic diester of glycolic acid.

In spite of its low solubility, this polymer has been fabricated into a variety of forms and structures. Extrusion, injection and compression molding as well as particulate leaching and solvent casting, are some of the techniques used to develop polyglycolide-based structures for biomedical applications (Gunatillake et al., 2006).

The high rate of degradation, acidic degradation products and low solubility however, limit the biomedical applications for PGA. Therefore, several copolymers containing glycolide units are being developed to overcome the inherent disadvantages of PGA.

Due to its hydrophilic nature, surgical sutures made of PGA tend to lose their mechanical strength rapidly, typically over a period of two to four weeks post-implantation. In order to adapt the materials properties of PGA to a wider range of possible applications, researchers undertook an intensive investigation of copolymers of PGA with the more hydrophobic PLA. 
Alternative sutures composed of copolymers of glycolic acid and lactic acid is currently marketed under the trade names Vicryl and Polyglactin 910 (Pachence et al., 2007).

Due to the presence of an extra methyl group in lactic acid, PLA is more hydrophobic than PGA. The hydrophobicity of high-molecular-weight PLA limits the water uptake of thin films to about $2 \%$ and results in a rate of backbone hydrolysis lower than that of PGA (Reed and Gilding, 1981). In addition, PLA is more soluble in organic solvents than is PGA.

Industrial lactic acid production utilizes the lactic fermentation process rather than synthesis because the synthetic routes have many major limitations, including limited capacity due to the dependency on a by-product of another process, inability to only make the desirable Llactic acid stereoisomer, and high manufacturing costs (Datta and Henry 2006). Three ways are possible for the polymerization of lactic acid (Jamshidian et al., 2010):

1. Direct condensation polymerization;

2. Direct poly-condensation in an azeotropic solution (an azeotrope is a mixture of 2 or more chemical liquids in such a ratio that its composition cannot be changed by simple distillation. This occurs because, when an azeotrope is boiled, the resulting vapor has the same ratio of constituents as the original mixture);

3. Polymerization through lactide formation.

Polymerization through lactide formation is being industrially accomplished for high molecular weight PLA production.

Recently, PLA, PGA, and their copolymers have been combined with bioactive ceramics such as Bioglass particles and hydroxyapatite that stimulate bone regeneration while greatly improving the mechanical strength of the composite material (Rezwan et al., 2006). Bioglass particles combined with D,L-PLA-co-PGA have also been shown to be angiogenic, suggesting a novel approach for providing a vascular supply to implanted devices. PLA, PGA, and their copolymers are also being intensively investigated for a large number of drug delivery applications.

\subsection{Polybutylene Succinate (PBS)}

Polybutylene succinate (PBS), chemically synthesized by polycondensation of 1,4-butanedial with succinic acid (Fig. 14), is a chemosynthetic polyester with a relatively high melting temperature $\left(\mathrm{T}_{\mathrm{m}} \sim 113^{\circ} \mathrm{C}\right)$ and favorable mechanical properties, which are comparable with those of such widely used polymers as polyethylene and polypropylene (Chen et al., 2011). PBS is thermoplastic, aliphatic polyester with many interesting properties including biodegradability, melt processability, and thermal and chemical resistance. In addition, its excellent processability in the field of both textiles into melt blown, multifilament, monofilament, nonwoven, flat, and split yarn fabrics and plastics into injection-molded products, makes it a promising polymer for various potential engineering applications (Lim et al., 2011). However, other properties of the PBS, such as its melt viscosity, melt strength, softness, and gas barrier characteristics are still regarded to be insufficient for various end-use applications. 
PBS has a relatively low biodegradation rate because of its high crystallization rate and high crystallinity. To promote the physical properties, extend the application field, and increase the biodegradability of PBS, numerous approaches have been used, such as physical blending, copolymerization, or formation of composites (Okamoto et al., 2003).

Owing to the excellent processability of PBS, it can be processed using conventional polyolefin equipment in the range $160-200{ }^{\circ} \mathrm{C}$. Injection, extrusion or blow moulding is suitable for processing PBS. Its applications include mulch film, cutlery, containers, packaging film, bags and flushable hygiene products.

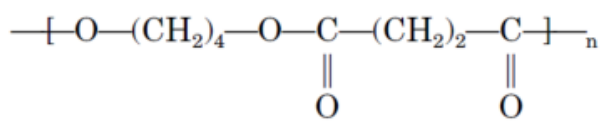

Figure 14. Chemical structure of polybutylene succinate (Okamoto et al., 2003)

\subsection{Polybutylene Succinate Adipate (PBSA)}

Because of the relatively low degradation rates, PBS can be copolymerized by adipate in order to increase the biodegradability. Poly (butylene succinate-co-adipate) (PBSA) is synthesized by the reaction of glycols with aliphatic dicarboxylic acids (Fig. 15) and is available for use in a variety of applications including films, laminations, sheet extrusion, monofilaments, multifilaments, blow-molded containers, injection molded cutlery, and foam cushions (Steeves et al., 2007). The succinic acid which is used to prepare this polymer is created by fermentation of sugar extracted from sugarcane or corn, therefore classifying it as a biobased material.

PBSA film has properties very similar to linear low-density polyethylene (LLDPE) and relatively high biodegradability, and is therefore suitable for a composting bag of kitchen waste (Ren et al., 2005).

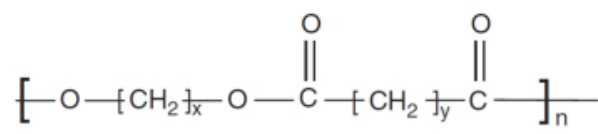

Figure 15. Chemical structure of polybutylene succinate adipate, where $x=4, y=2,4$ (Steeves et al., 2007)

\subsubsection{Poly (Vinyl Alcohol) (PVOH) and Poly (Vinyl Acetate) (PVA)}

Poly (vinyl alcohol) (PVOH) is the most readily biodegradable of vinyl polymers. It is readily degraded in waste-water-activated sludges. Unlike many vinyl polymers, $\mathrm{PVOH}$ is not prepared by polymerization of the corresponding monomer. The monomer, vinyl alcohol, almost exclusively exists as the tautomeric form, acetaldehyde. $\mathrm{PVOH}$ instead is prepared by partial or complete hydrolysis of polyvinyl acetate to remove acetate groups (Fig. 16). PVOH 
has a melting point of 180 to $190^{\circ} \mathrm{C}$. It has a molecular weight of between 26,300 and 30,000 , and a degree of hydrolysis of 86.5 to $89 \%$ (Ramaraj, 2007).

$\mathrm{PVOH}$ is an odorless and tasteless, translucent, white or cream colored granular powder. It is used as a moisture barrier film for food supplement tablets and for foods that contain inclusions or dry food with inclusions that need to be protected from moisture uptake. PVOH belongs to the water soluble polymers. In the context of the application, solubility and speed of solution are important characteristics.

PVOH has excellent film forming, emulsifying and adhesive properties. It is also resistant to oil, grease and solvents. It has high tensile strength and flexibility, as well as high oxygen and aroma barrier properties. However these properties are dependent on humidity, in other words, with higher humidity more water is absorbed. The water, which acts as a plasticizer, will then reduce its tensile strength, but increase its elongation and tear strength. $\mathrm{PVOH}$ is fully degradable and dissolves quickly (Vercauteren and Donners, 1986).

$\mathrm{PVOH}$ is the largest synthetic water-soluble polymer produced in the world. The prominent properties of $\mathrm{PVOH}$ may include its biodegradability in the environment. The generally accepted biodegradation mechanism occurs via a two-step reaction by oxidation of hydroxyl group followed by hydrolysis. The biodegradation of $\mathrm{PVOH}$ is influenced by the stereochemical configuration of the hydroxyl groups of PVOH. The isotactic material of $\mathrm{PVOH}$ preferentially degraded. The microbial degradation of PVOH has been studied, as well as its enzymatic degradation by secondary alcohol peroxidases isolated from soil bacteria of the Pseudomonas strain (Jansson et al., 2006).

$\mathrm{PVOH}$ has been studied extensively because of its good biodegradability and mechanical properties. These properties have made PVOH as attractive material for disposable and biodegradable plastic substitutes. Its water solubility, reactivity, and biodegradability make it a potentially useful material in biomedical, agricultural, and water treatment areas, e.g. as a flocculant, metal-ion remover, and excipient for controlled release systems.

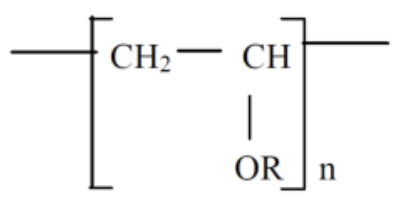

Figure 16. Chemical structure of poly (vinyl alcohol), Where $\mathrm{R}=\mathrm{H}$ or $\mathrm{COCH}_{3}($ Ramaraj, 2007)

Polyvinyl acetate, (PVA), is a rubbery synthetic polymer. It is a type of thermoplastic and belongs to the polyvinyl esters family. Polyvinyl acetate is prepared by polymerization of vinyl acetate monomer (free radical vinyl polymerization of the monomer vinyl acetate) (Fig. 17). The degree of polymerization of polyvinyl acetate typically is 100 to 5000 . The ester groups of the polyvinyl acetate are sensitive to base hydrolysis and will slowly convert PVA into polyvinyl alcohol and acetic acid. Under alkaline conditions, boron compounds such as boric 
acid or borax cause the polymer to cross-link, forming tackifying precipitates or slime (Dionisio et al., 1993).

PVA reportedly undergoes biodegradation more slowly. Copolymers of ethylene and vinyl acetate were susceptible to slow degradation in soil-burial tests. The weight loss in a 120-day period increased with increasing acetate content. Because PVOH is obtained from the hydrolysis of PVA, which can be controlled easily in terms of the extent of hydrolysis and the sequence of PVA and PVOH, a controlled hydrolysis of PVA followed by controlled oxidation should provide degradation materials having a wide range of properties and degradability.

Polyvinyl acetate is a component of a widely used glue type, commonly referred to as wood glue, white glue, carpenter's glue, or PVA glue. The stiff homopolymer PVA, mostly the more soft copolymer a combination of vinyl acetate and ethylene, vinyl acetate ethylene (VAE), is used also in paper coatings, paint and other industrial coatings, as binder in nonwovens in glass fibers, sanitary napkins, filter paper and in textile finishing (Chandra and Rustgi, 1998).

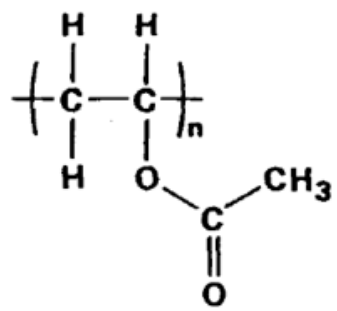

Figure 17. Chemical structure of poly (vinyl acetate) (Chandra and Rustgi, 1998)

\section{Factors affecting biodegradation}

Several factors affect extent of polymer biodegradation that most impotents of them are polymer structure, polymer morphology, molecular weight, Radiation and chemical treatments.

\subsection{Polymer structure}

Natural macromolecules, e.g. protein, cellulose, and starch are generally degraded in biological systems by hydrolysis followed by oxidation. It is not surprising, then, that most of the reported synthetic biodegradable polymers contain hydrolyzable linkages along the polymer chain; for example, amide enamine, ester, urea, and urethane linkages are susceptible to biodegradation by microorganisms and hydrolytic enzymes. Since many proteolytic enzymes specifically catalyze the hydrolysis of peptide linkages adjacent to substituents in proteins, substituted polymers containing substituents such as benzyl, hydroxy, carboxy, methyl, and phenyl groups have been prepared in the hope that an introduction of these substituents might increase biodegradability (Savenkova et al., 2000). 
Since most enzyme-catalyzed reactions occur in aqueous media, the hydrophilic-hydrophobic character of synthetic polymers greatly affects their biodegradabilities. A polymer containing both hydrophobic and hydrophilic segments seems to have a higher biodegradability than those polymers containing either hydrophobic or hydrophilic structures only. A series of poly(alkylene tartrate)s was found to be readily assimilated by Aspergillus niger.

However, the polymers derived from $\mathrm{C}_{6}$ and $\mathrm{C}_{8}$ alkane diols were more degradable than the more hydrophilic polymers derived from $\mathrm{C}_{2}$ and $\mathrm{C}_{4}$ alkane diols or the more hydrophobic polymers derived from the $\mathrm{C}_{10}$ and $\mathrm{C}_{12}$ alkane diols.

In order for a synthetic polymer to be degradable by enzyme catalysis, the polymer chain must be flexible enough to fit into the active site of the enzyme. This most likely accounts for the fact that, whereas the flexible aliphatic polyesters are readily degraded by biological systems, the more rigid aromatic poly (ethylene terephthalate) is generally considered to be bioinert (Chandra and Rustgi, 1998).

\subsection{Polymer morphology}

One of the principal differences between proteins and synthetic polymers is that proteins do not have equivalent repeating units along the polypeptide chains. This irregularity results in protein chains being less likely to crystallize. It is quite probable that this property contributes to the ready biodegradability of proteins. Synthetic polymers, on the other hand, generally have short repeating units, and this regularity enhances crystallization, making the hydrolyzable groups inaccessible to enzymes. It was reasoned that synthetic polymers with long repeating units would be less likely to crystallize and thus might be biodegradable; indeed, a series of poly (amide-urethane)s were found to be readily degraded by subtilisin (Zilberman et al., 2005).

Selective chemical degradation of semicrystalline polymer samples shows certain characteristic changes. During degradation, the crystallinity of the sample increases rapidly at first, then levels off to a much slower rate as the crystallinity approaches $100 \%$. This is attributed to the eventual disappearance of the amorphous portions of the sample. The effect of morphology on the microbial and enzymatic degradation of PCL, a known biodegradable polymer with a number of potential applications, has been studied. Scanning electron microscopy (SEM) has shown that the degradation of a partially crystalline PCL film by filamentous fungi proceeds in a selective manner, with the amorphous regions being degraded prior to the degradation of the crystalline region. The microorganisms produce extracellular enzymes responsible for the selective degradation. This selectivity can be attributed to the less-ordered packing of amorphous regions, which permits easier access for the enzyme to the polymer chains. The size, shape and number of the crystallites all have a pronounced effect on the chain mobility of the amorphous regions and thus affect the rate of the degradation. This has been demonstrated by studying the effects of changing orientation via stretching on the degradation (Chandra and Rustgi, 1998).

Biodegradation proceeds differently from chemical degradation. Studies on the degradation by solutions of $40 \%$ aqueous methylamine have shown a difference in morphology and 
molecular weight changes and in the ability of the degrading agents to diffuse into the substrate. Also, it was found that the differences in degradation rates between amorphous and crystalline regions are not same. The enzyme is able to degrade the crystalline regions faster than can methylamine. Quantitative GPC (gel permeation chromatography) analysis shows that methylamines degrade the crystalline regions, forming single and double transverse length products. The enzyme system, on other hand, shows no intermediate molecular weight material and much smaller weight shift with degradation. This indicates that although degradation is selective, the crystalline portions are degraded shortly after the chain ends are made available to the exoenzyme. The lateral size of the crystallites has a strong effect on the rate of degradation because the edge of the crystal is where degradation of the crystalline material takes place, due to the crystal packing. A smaller lateral crystallite size yields a higher crystallite edge surface in the bulk polymer. Prior to the saturation of the enzyme active sites, the rate is dependent on available substrate; therefore, a smaller lateral crystallite size results in a higher rate of degradation. The degradation rate of a PCL film is zero order with respect to the total polymer, but is not zero order with respect to the concentrations of the crystallite edge material. The drawing of PCL films causes an increase in the rate of degradation, whereas annealing of the PCL causes a decrease in the rate of degradation. This is probably due to opposite changes in lateral crystallite sizes.

In vitro chemical and enzymatic degradations of polymers, especially polyesters, were analyzed with respect to chemical composition and physical properties. It was found quite often that the composition of a copolymer giving the lowest melting point is most susceptible to degradation (Vert, 2005). The lowest packing order, as expected, corresponds with the fastest degradation rate.

\subsection{Radiation and chemical treatments}

Photolysis with UV light and the $\gamma$-ray irradiation of polymers generate radicals and/or ions that often lead to cleavage and crosslinking. Oxidation also occurs, complicating the situation, since exposure to light is seldom in the absence of oxygen. Generally this changes the material's susceptibility to biodegradation. Initially, one expects the observed rate of degradation to increase until most of the fragmented polymer is consumed and a slower rate of degradation should follow for the crosslinked portion of the polymer. A study of the effects of UV irradiation on hydrolyzable polymers confirmed this. Similarly, photooxidation of polyalkenes promotes (slightly in most cases) the biodegradation. The formation of carbonyl and ester groups is responsible for this change (Miller and Williams, 1987).

Processes have been developed to prepare copolymers of alkenes containing carbonyl groups so they will be more susceptible to photolytic cleavage prior to degradation. The problem with this approach is that negligible degradation was observed over a two year period for the buried specimens. Unless a prephotolysis arrangement can be made, the problem of plastic waste disposal remains serious, as it is undesirable to have open disposal, even with constant sunlight exposure.

As expected, $\gamma$-ray irradiation greatly affects the rate of in vitro degradation of polyesters. For polyglycolide and poly(glycolide-co-lactide), the $\mathrm{pH}$ of the degradation solution de- 
creased as the process proceeded. The change-time curves exhibit sigmoidal shapes and consist of three stages: early, accelerated, and later; the lengths of these three regions were a function of $\gamma$-ray irradiation. Increasing radiation dosage shortens the time of the early stage. The appearance of the drastic $\mathrm{pH}$ changes coincides with loss of tensile breaking strength. Similar effects via enzymatic and microbial degradation remain to be demonstrated (Chandra and Rustgi, 1998).

\subsection{Molecular weight}

There have been many studies on the effects of molecular weight on biodegradation processes. Most of the observed differences can be attributed to the limit of detecting the changes during degradation, or, even more often, the differences in morphology and hydrophilicityhydrophobicity of polymer samples of varying molecular weight. Microorganisms produce both exoenzymes [degrading polymers from terminal groups (inwards)] and endoenzymes (degrading polymers randomly along the chain). One might expect a large molecular effect on the rate of degradation in the ease of exoenzymes and a relatively small molecular weight effect in the case of endoenzymes. Plastics remain relatively immune to microbial attack as long as their molecular weight remains high. Many plastics, such as poly ethylene, poly propylene and poly styrene do not support microbial growth. Low molecular weight hydrocarbons, however, can be degraded by microbes. They are taken in by microbial cells, 'activated' by attachment to coenzyme-A, and converted to cellular metabolites within the microbial cell. However, these processes do not function well (if at all) in an extracellular environment, and the plastic molecules are too large to enter the cell. This problem does not arise with natural molecules, such as starch and cellulose, because conversions to low molecular weight components by enzyme reactions occur outside the microbial cell. Photodegradation or chemical degradation may decrease molecular weight to the point that microbial attack can proceed, however (Chandra and Rustgi, 1998).

The upper limits of molecular weight, beyond which uptake and intracellular degradation do not occur, have not been established for all alkane-derived materials. Very slow degradation of paraffins, PE glycols, and linear alkyl benzene sulphonates occurs when the length of the polymer chain exceeds 24-30 carbon atoms. It could be concluded from these amply documented results that alkane-based plastics with molecular weights exceeding 400-500 daltons (i.e. greater than 30 carbon atoms) must be degraded into smaller molecules by photodegradation, chemical or other biological means before biodegradation. LDPE with a molecular weight average of $M w=150000$ contains about 11000 carbon atoms. Decreasing molecules of this size to biologically acceptable dimensions requires extensive destruction of the PE matrix. This destruction can be partly accomplished in blends of PE and biodegradable natural polymers by the action of organisms, such as arthropods, millipedes, crickets, and snails (Santerre et al., 2005).

\section{Future strategy}

Synthetic polymers are gradually being replaced by biodegradable materials especially those derived from replenishable, natural resources. Bioplastics development is just beginning; until 
now it covers approximately $5-10 \%$ of the current plastic market, about 50,000 $t$ in Europe. More than the origin, the chemical structure of the biopolymer that determines its biodegradability. Use of such biopackagings will open up potential economic benefits to farmers and agricultural processors. The principal field regards the use of packaging films for food products, loose films used for transport packaging, service packaging like carry bags, cups, plates and cutlery, biowaste bags, in agricultural and horticultural fields like bags and compostable articles. Bilayer and multicomponent films resembling synthetic packaging materials with excellent barrier and mechanical properties need to be developed. Crosslinking, either chemically or enzymatically, of the various biomolecules is yet another approach of value in composite biodegradable films. Sustained multidisciplinary research efforts by chemists, polymer technologists, microbiologists, chemical engineers, environmental scientists and bureaucrats are needed for a successful implementation and commercialization of biopolymer-based eco-friendly packaging materials. Undoubtedly, biodegradation offers an attractive route to environmental waste management. Their development costs are high and yet they do not have the benefit of economic scale. It was shown that polyolefins present the same oxo-biodegradability of biopolymers, but they are more economical and effecting during use. Bio-based polymers have already found important applications in medicine field, where cost is much less important than function. It seems very unlikely that biodegradable oil based polymers will be displaced from their current role in packaging application, where cost is more important for the consumer market than environmental acceptability. Biopolymers fulfill the environmental concerns but they show some limitations in terms of performance like thermal resistance, barrier and mechanical properties, associated with the costs. Then, this kind of packaging materials needs more research, more added value like the introduction of smart and intelligent molecules (which is the nanotechnology field) able to give information about the properties of the material inside the package (quality, shelf-life, safety) and nutritional values. It is necessary to make researches on this kind of material to enhance barrier properties, to incorporate intelligent labelling, to give to the consumer the possibility to have more detailed product information than the current system.

\section{Author details}

Babak Ghanbarzadeh and Hadi Almasi

University of Tabriz, Iran

\section{References}

[1] Almasi, H, Ghanbarzadeh, B, \& Entezami, A. A. (2010). Physicochemical properties of starch-CMC-nanoclay biodegradable films. International Journal of Biological Macromolecules. , 46, 1-5. 
[2] Amass, W, Amass, A, \& Tighe, B. (1998). A review of biodegradable polymers: Uses, current developments in the synthesis and characterization of biodegradable polyesters, blends of biodegradable polymers, and recent advances in biodegradation studies. Polymer International. , 47, 89-144.

[3] Angles, M. N, \& Dufresne, A. (2000). Plasticized starch/tunicin whiskers nanocomposites. Macromolecules. , 33(22), 8344-8353.

[4] Argos, P, Pederson, K, Marks, M. D, \& Larkins, B. A. (1982). Structure Model for Maize Zein Proteins. Journal of Biological Chemistry. , 257, 9984-9990.

[5] Arvanitoyannis, I, Nakayama, A, \& Aiba, S. (1998). Chitosan and Gelatin Based Edible Films: State Diagrams, Mechanical and Permeation Properties. Carbohydrate Polymers. , 37, 371-382.

[6] Augst, A. D, Kong, H. J, \& Mooney, D. J. (2006). Alginate hydrogels as biomaterials. Macromolecular Bioscience. , 6(8), 623-33.

[7] Averous, L. (2002). Starch based biodegradable materials suitable for thermoforming packaging. Starch/Starke. , 53, 368-371.

[8] Balassa, L. L, \& Fanger, G. O. (1971). Microencapsulation in the food industry. CRC Critical Reviews in Food Technology. , 2, 245-265.

[9] Bielecki, S, Krystynowicz, A, Turkiewicz, L, \& Kalinowska, H. (2004). Bacterial cellulose. In: Biopolymers. ed. Steinbüchel, A., ( Wiley-VCH., 3-7.

[10] Blanshard, J. M. V. (1987). Starch granule structure and function: a physicochemical approach. In Starch: Properties and potential. Galliard, T., ed ( Chichester: John Wiley \& Sons., 16-54.

[11] Bouhadir, K. H, Lee, K. Y, Alsberg, E, Damm, K. L, Anderson, K. W, \& Mooney, D. J. (2001). Degradation of partially oxidized alginate and its potential application for tissue engineering. Biotechnology Progress. , 17, 945-50.

[12] Brendel, O, Iannetta, P. P. M, \& Stewart, D. and simple method to isolate pure alphacellulose. Phytochemical Analysis. , 11, 7-10.

[13] Buleon, A, Colonna, P, Planchot, V, \& Ball, S. (1998). Starch granules: structure and biosynthesis. International Journal of Biological Macromolecules. , 23, 85-112.

[14] Buonocore, G. G. Del Nobile, M.A., Martino, C.D., Gambacorta, G., La Notte, E., and Nicolais, L. ((2003). Modeling the water transport properties of casein-based edible coating. Journal of Food Engineering. , 60, 99-106.

[15] Byrom, D. (1992). Production of poly- $\beta$-hydroxybutyrate and poly- $\beta$-hydroxyvalerate copolymers. FEMS Microbiology Reviews. , 103, 247-250. 
[16] Cao, Y, Wu, J, Zhang, J, Li, H. Q, Zhang, Y, \& He, J. S. (2009). Room temperature ionic liquids (RTILs): a new and versatile platform for cellulose processing and derivatization. Chemical Engineering Journal. , 147, 13-21.

[17] Caoa, N, Fua, Y, \& Hea, J. (2007). Preparation and physical properties of soy protein isolate and gelatin composite films. Food Hydrocolloids. , 21, 1153-1162.

[18] Chandra, R, \& Rustgi, H. (1998). Biodegradable polymers. Progress in Polymer Science. , 23, 1273-1335.

[19] Chen, C. H, Yang, C. S, Chen, M, Shih, Y. C, Hsu, H. S, \& Lu, S. F. (2011). Synthesis and characterization of novel poly(butylene succinate-co-2-methyl-1,3-propylene succinate)s. eXPRESS Polymer Letters. , 5(4), 284-294.

[20] Chen, G. Q, \& Page, W. J. (1997). Production of poly-beta-hydroxybutyrate by Azotobacter vinelandii UWD in a two-stage fermentation process. Biotechnological Biotechniques. , 11, 347-350.

[21] Chen, G. Q, Zhang, G, Park, S. J, \& Lee, S. (2001). Industrial Production of Poly(hydroxy- butyrate-co- hydroxyhexanoate). Applied Microbiological Biotechnology. , 57, 50-55.

[22] Choa, S. Y, \& Rhee, C. (2004). Mechanical properties andwater vapor permeability of edible films made from fractionated soy proteins with ultrafiltration. LWT. , 37, 833-839.

[23] Cuq, B, Gontard, N, \& Guilbert, S. (1998). Proteins as Agricultural Polymers for Packaging Production. Cereal Chemistry. , 75(1), 1-9.

[24] Dalgleish, D. G. (1997). Structure-Function Relationships of Caseins. In Food Proteins and Their Applications. eds., S. Damodaran and A. Paraf. ( New York: Marcel Dekker., 199-223.

[25] Datta, R, \& Henry, M. (2006). Lactic acid: recent advances in products, processes and technologies: a review. Journal of Chemical Technology and Biotechnology. , 81, 1119-1129.

[26] Debeaufort, F, \& Voilley, A. (1997). Methylcellulose-based edible films and coatings: 2. Mechanical and thermal properties as a function of plasticizer content. Journal of Agricultural and Food Chemistry. , 45(3), 685-689.

[27] Dionisio, M. S, Moura-ramos, J. J, \& Williams, G. (1993). Molecular motion in poly (vinyl acetate) and in poly (vinyl acetate) / Q-nitroaniline mixtures. Polymer. , 34(19), 4105-4113.

[28] Doi, Y, Kanesawa, Y, Kunioka, M, \& Saito, T. (1990). Biodegradation of microbial copolyesters: poly(3-hydroxy-butyrate-co-3-hydroxyvalerate) and poly(3-hydroxybutyrate-co-4-hydroxyvalerate). Macromolecules. , 23, 26-31. 
[29] Dufresne, A, \& Cavaille, J. Y. (1998). Clustering and percolation effects in microcrystalline starch reinforced thermoplastic. Journal of Polymer Science: Part B. , 36(12), 2211-2224.

[30] Dybing, S. T, \& Smith, D. E. (1991). Relation of Chemistry and Processing Procedures to Whey Protein Functionality: A Review. Cultured Dairy Products Journal. , 26, $4-12$.

[31] Edgar, K. J, Buchanan, C. M, Debenham, J. S, Rundquist, P. A, Seiler, B. D, Shelton, M. C, \& Tindall, D. (2001). Advances in cellulose ester performance and application. Progress in Polymer Science. , 26, 1605-1688.

[32] Eggink, G, De Waard, P, \& Huijberts, G. N. M. (1995). Formation of novel poly(hydroxy- alkanoates) from long-chain fatty acids. Canadian Journal of Microbiology. , 41(1), 14-21.

[33] Espigares, I, Elvira, C, Mano, J. F, \& Vazquez, B. San Roman, J., and Reis, R.L. ((2002). New partially degradable and bioactive acrylic bone cements based on starch blends and ceramic fillers. Biomaterials. , 23, 1883-95.

[34] Fabra, M, Talens, P, \& Chiralt, A. (2009). Microstructure and optical properties of sodium caseinate films containing oleic acid-beeswax mixtures. Food Hydrocolloids. , 23, 676-683.

[35] Fang, J, \& Fowler, P. (2003). The use of starch and its derivatives as biopolymer sources for packaging materials. Food, Agriculture \& Environment. , 1, 82-84.

[36] FDA (2002). Inventory of Effective Food Contact Substance (FCS) Notifications http:// www.accessdata.fda.gov/scripts/fcn/fcnDetailNavigation.cfm?rpt=fcsListing\&id=178. (178)

[37] Feng, X. D, Song, C. X, \& Chen, W. Y. (1983). Synthesis and evaluation of biodegradable block copolymers of E-caprolactone and d,l-lactide. Journal of Polymer Science. , 21, 593-600.

[38] Fox, P. F, \& Mcsweeney, P. L. H. (1998). Dairy Chemistry and Biochemistry. London: Blackie Academic \& Professional.

[39] Galbe, M, \& Zacchi, G. (2002). A review of the production of ethanol from softwood. Applied Microbiological Biotechnology. , 59, 618-628.

[40] Gennadios, A. (2002). Protein- based films and coatings. ( CRC Press LLC., 134-149.

[41] Ghanbarzadeh, B, Almasi, H, \& Entezami, A. A. (2011). Improving the barrier and mechanical properties of corn starch-based edible films: Effect of citric acid and carboxymethyl cellulose. Industrial Crops and Products. , 33, 229-235.

[42] Ghanbarzadeh, B, Almasi, H, \& Entezami, A. A. (2010). Physical properties of edible modified starch/carboxymethyl cellulose films. Innovative Food Science and Emerging Technologies. , 11, 697-702. 
[43] Ghanbarzadeh, B, \& Almasi, H. (2011). Physical properties of edible emulsified films based on carboxymethyl cellulose and oleic acid. International Journal of Biological Macromolecules. , 48, 44-49.

[44] Ghanbarzadeh, B, Musavi, M, Oromiehie, A. R, \& Rezayi, K. Razmi Rad, E., and Milani, J. ((2007). Effect of plasticizing sugars on water vapor permeability, surface energy and microstructure properties of zein films. LWT. , 40, 1191-1197.

[45] Ghanbarzadeh, B, Oromiehie, A, Musavi, M, \& Rezayi, K. Razmi Rad, E., and Milani, J. ((2006c). Investigation of water vapour permeability, hydrophobicity and morphology of zein films plasticized by polyols. Iranian Polymer Journal. , 15(7), 34-42.

[46] Ghanbarzadeh, B, Oromiehie, A. R, Musavi, M, Emam, D-J. o. m. e. h, Razmi, Z, Rad, E, \& Milani, J. (2006a). Effect of plasticizing sugars on rheological and thermal properties of zein resins and mechanical properties of zein films. Journal of Food Research International. , 39, 882-890.

[47] Ghanbarzadeh, B, Oromiehie, A. R, \& Musavi, M. Massimiliano Falcone, P., Emam D-Jomeh, Z., and Razmi Rad, E. ((2007b). Study of Mechanical Properties, Oxygen Permeability and AFM Topography of Zein Films Plasticized by Polyols. Packaging Technology and Science. , 20, 155-163.

[48] Ghanbarzadeh, B, \& Oromiehie, A. R. Musavi, Razmi Rad, E., and Milani, J. ((2006b). Effect of Polyolic Plasticizers on Rheological and Thermal Properties of Zein Resins. Iranian Polymer Journal. , 15(10), 779-787.

[49] Ghanbarzadeh, B, Orumiei, A. R, \& Saboonchi, S. H. (2008). Corona treatment: effect on properties of chitosan coated corn prolamin films. International chemical engineering congress. Kish island; January., 2-5.

[50] Gounga, M. E, Xu, S, \& Wang, Z. (2007). Whey protein isolate-based edible films as affected by protein concentration, glycerol ratio and pullulan addition in film formation. Journal of Food Engineering. , 83, 521-530.

[51] Gruessner, U, Clemens, M, Pahlplatz, P. V, Sperling, P, Witte, J, \& Sperling, P. (2001). Improvement of perineal wound healing by local administration of gentamicin-impregnated collagen fleeces after abdominoperineal excision of rectal cancer. American Journal of Surgery. , 182, 502-9.

[52] Guilbert, S, Gontard, N, \& Gorris, L. G. M. (1996). Prolongation of the Shelf-life of Perishable Food Products Using Biodegradable Films and Coatings. Food Science and Technology. , 29, 10-17.

[53] Gunatillake, P, Mayadunne, R, \& Adhikari, R. (2006). Recent developments in biodegradable synthetic polymers. Biotechnology Annual Reviews. , 12, 301-347.

[54] Hall, P. E, Sanderson, S. M, Johnston, D. M, \& Cannon, R. E. (1992). Transformation of Acetobacter xylinum with plasmid DNA by electroporation Plasmid. , 28(3), 194-200. 
[55] Hamad, W. (2006). On the Development and Applications of Cellulosic Nanofibrillar and Nanocrystalline Materials. The Canadian Journal of Chemical Engineering. , 84, 513-519.

[56] Handa, A, Gennadios, A, Froning, G. W, Kuroda, N, \& Hanna, M. A. (1999). Tensile, Solubility, and Electrophoretic Properties of Egg White Films as Affected by Surface Sulfhydryl Groups. Journal of Food Science. , 64(1), 68-76.

[57] Hebert, G. D, \& Holloway, O. E. (1992). Product and process of coating nuts with edible protein. U.S. patent $5,149,562$.

[58] Holland, S. J, Jolly, A. M, Yasin, M, \& Tighe, B. J. (1987). Polymers for biodegradable medical devices II. Hydroxybutyrate-hydroxyvalerate copolymers: hydrolytic degradation studies. Biomaterials. , 8, 289-295.

[59] Hood, L. L. (1987). Collagen in Sausage Casings. In: Advances in Meat Research, eds., A.M. Pearson, T.R. Dutson and A.J. Bailey, ( New York: Van Nostrand Reinhold., 4, 109-129.

[60] Hu, W, Chen, S, Xu, Q, \& Wang, H. (2011). Solvent-free acetylation of bacterial cellulose under moderate conditions. Carbohydrate Polymers. , 83, 1575-1581.

[61] Iguchi, M, Yamanaka, S, \& Budhiono, A. (2000). Bacterial cellulose-a masterpiece of nature arts. Journal of Materials Science. , 35, 261-270.

[62] Iwata, T, Tsunoda, K, Aoyagi, Y, Kusaka, S, Yonezawa, N, \& Doi, Y. (2003). Mechanical properties of uniaxially cold-drawn films of poly( $\beta$-3-hydroxybutyrate). Polymer Degradation and Stability. , 79, 217-224.

[63] Jacob JohnM., and Thomas, S. ((2008). Biofibres and biocomposites. Carbohydrate Polymers. , 71, 343-364.

[64] Jamshidian, M. Arab Tehrany, E., Imran, M., Jacquot, M., and Desobry, S. ((2010). Poly-Lactic Acid: Production, Applications, Nanocomposites, and Release Studies. Comprehensive Reviews in Food Science and Food Safety. , 9, 552-572.

[65] Jane, J, Lim, S, Paetau, I, Spence, K, \& Wang, S. (1994). Biodegradable plastics made from agricultural biopolymers. In: Polymers from Agricultural Coproducts. M. L. Fishman, R. B. Friedman, and S. J. Huang, eds. (p.p. 92-100). ACS Symposium Series 575: Chicago.

[66] Jansson, A, Järnström, A, Rättö, P, \& Thuvander, F. (2006). Physical and Swelling Properties of Spray-Dried Powders made from Starch and Poly(vinyl alcohol). Starch/Stärke. , 58, 632-641.

[67] Johnston-banks, F. A. (1990). Gelatine. In Food Gels. ed., P. Harris. ( New York: Elsevier Applied Science., 233-289. 
[68] Kabir, M. M, Wang, H. K. T, \& Cardona, F. (2012). Chemical treatments on plantbased natural fibre reinforced polymer composites: An overview. Composites: Part B. In Press Paper.

[69] Kasarda, D. D. (1999). Glutenin Polymers: The In Vitro to In Vivo Transition. Cereal Foods World. , 44, 566-572.

[70] Kim, Y. B, Rhee, Y. H, Han, S. H, Heo, G. S, \& Ki, J. S. (1996). Poly-3-hydroxyalkanoates produced from Pseudomonas oleovorans grown with !-phenoxyalkanoates. Macromolecules, , 29, 3432-3435.

[71] Knauf, M, \& Moniruzzaman, M. (2004). Lignocellulosic biomass processing: a perspective. International Sugar Journal. , 106, 147-150.

[72] Krochta, J. M. (1992). Control of Mass Transfer in Foods with Edible Coatings and Films. In Advances in Food Engineering. eds, R.P. Singh and M.A. Wirakartakasumah, Boca Raton, FL. ( CRC Press, Inc., 517-538.

[73] Kulesa, G. (1999). Clean fractionation-inexpensive cellulose for plastics production. http://

[74] La MantiaF.P., and Morreale, M. ((2011). Green composites: A brief review. Composites: Part A. , 42, 579-588.

[75] Lai, H. M, \& Padua, G. W. (1997). Properties and Microstructure of plasticized zein films. Cereal Chemistry. , 74(6), 771-775.

[76] Lai, L. S, \& Kokini, J. L. (1991). Physiochemical changes and rheological properties of starch during extrusion (a review). Biotechnology Progress. , 7, 251-266.

[77] Lim, S, Lee, J, Jang, S, Lee, S, Lee, K, Choi, H, \& Chin, J. (2011). Synthetic Aliphatic Biodegradable Poly(butylene succinate)/Clay Nanocomposite Foams with High Blowing Ratio and Their Physical Characteristics. Polymer Engineering and Science. , $123,1316-1325$.

[78] Lircks, J. (1998). Properties and applications of compostable starch-based plastic material.

[79] Lutke-eversloh, T, Bergander, K, Luftman, H, \& Steinbuchel, A. (2001). Identification of a new class of biopolymer: bacterial synthesis of a sulfur-containing polymer with thioester linkages. Microbiology. , 147, 11-19.

[80] Madsen, B. (2004). Properties of plant fiber yarn polymer composites. PhD thesis, BYGDTU, Technical University of Denmark; 8-77877-145-5

[81] Mao, L. J, Imam, S, Gordon, S, Cinelli, P, \& Chiellini, E. (2000). Extruded cornstarchglycerol- polyvinyl alcohol blends: Mechanical properties, morphology, and bio degradability. Journal of Polymers and the Environment. , 8(4), 205-211. 
[82] Maurus, P. B, \& Kaeding, C. C. (2004). Bioabsorbable implant material review. Operation Techniques and Sport Medicine. , 12, 158-60.

[83] Mehta, R, Kumar, V, Bhunia, H, \& Upadhyay, S. N. (2005). Synthesis of poly (lactic acid): a review. Journal of Macromolecular Science and Polymer Review. , 45, 325-49.

[84] Miller, N. D, \& Williams, D. F. (1987). On the biodegradation of poly- $\beta$-hydroxybutyrate $(\mathrm{PHB})$ homopolymer and poly-b-hydroxybutyrate- hydroxyvalerate copolymers. Biomaterials. , 8, 129-137.

[85] Mithieux, S. M, Rasko, J. E. J, \& Weiss, A. S. (2004). Synthetic elastin hydrogels derived from massive elastic assemblies of selforganized human protein monomers. Biomaterials. , 25, 4921-4927.

[86] Mohanty, A. K, Misra, M, \& Hinrichsen, G. (2000). Biofibres, biodegradable polymers, and biocompostites: an overview. Macromolecular Materials Engineering. , $276,1-24$.

[87] Muller, L. L. (1982). Manufacture of Casein, Caseinates and Coprecipitates. In Developments in Dairy Chemistry-1. Proteins. ed., P.F. Fox ( London: Applied Science Publishers., 315-337.

[88] Nair, L. S, Bijoux, C, Trevor, S, \& Laurencin, C. T. (2006). Development of injectable thermogelling chitosan-inorganic phosphate solution for biomedical application. Social Biomaterial Meeting.

[89] Naira, L. S, \& Laurencin, C. T. (2007). Biodegradable polymers as biomaterials. Progress in Polymer Science. , 32, 762-798.

[90] Nakamura, E. M, Cordi, L, Almeida, G. S. G, Duran, N, \& Mei, L. H. I. (2005). Study and development of LDPE/starch partially biodegradable compounds. Journal of Materials Processing Technology. , 162, 236-241.

[91] Nampoothiri, K. M, Nair, N. R, \& John, R. P. (2010). An overview of the recent developments in polylactide (PLA) research. Bioresource Technology. , 101, 8493-8501.

[92] Okamoto, K, Ray, S. S, \& Okamoto, M. (2003). New Poly (butylene succinate)/ Layered Silicate Nanocomposites. II. Effect of Organically Modified Layered Silicates on Structure, Properties, Melt Rheology, and Biodegradability. Journal of Polymer Science: Part B: Polymer Physics. , 41, 3160-3172.

[93] Olesen, P. O, \& Plackett, D. V. (1999). Perspectives on the performance of natural plant fibres presented at natural fibres performance forum.Copenhagen, May http:// www.ienica.net/fibreseminar/olesen.pdf/>., 27-28.

[94] Onishi, H, Takahashi, H, Yoshiyasu, M, \& Machida, Y. (2001). Preparation and in vitro properties of N-Succinylchitosan or carboxymethylchitin-mitomycin C conjugate microparticles with specified size. Drug Delivery Industry in Pharmaceutical. , 27, 659-67. 
[95] Ozdemir, M, \& Floros, J. D. (2008). Optimization of edible whey protein films containing preservatives for mechanical and optical properties. Journal of Food Engineering. , 84, 116-123.

[96] Pachence, J. M, Bohrer, M. P, \& Kohn, J. (2007). Biodegradable Polymers. In Principles of Tissue Engineering, Lanza, B., Langer, C., and Vacanti, P., edr. 3rd Edition. (Elsevier, Inc, 323.

[97] Pedroso, A. G, \& Rosa, D. S. (2005). Mechanical, thermal and morphological characterization of recycled LDPE/corn starch blends. Carbohydrate Polymers. , 59, 1-9.

[98] Pereira, C. S, Cunha, A. M, Reis, R. L, \& Vazquez, B. and San Roman, J. ((1998). New starch-based thermoplastic hydrogels for use as bone cements or drug-delivery carriers. Journal of Material Science. , 12, 825-33.

[99] Peressini, D, Bravin, B, Lapasin, R, Rizzotti, C, \& Sensidoni, A. (2003). Starch-methylcellulose based edible films: rheological properties of film-forming dispersions. Journal of Food Engineering. , 59, 25-32.

[100] Pitt, C. G, Andrady, A. L, Bao, Y. T, \& Sarnuei, N. K. P. (1987). Estimation of the rate of drug diffusion in polymers. In: Controlled-Release Technology, Pharmaceutical Applications. eds.P. I. Lee and W. R. Good, ( American Chemical Society, Washington, DC., 49-77.

[101] Pszczola, D. E. (1998). Addressing Functional Problems in Fortified Foods. Food Technology. 52(7):38, 40-41, 44, 46.

[102] Ramaraj, B. (2007). Crosslinked Poly(vinyl alcohol) and Starch Composite Films. II. Physicomechanical, Thermal Properties and Swelling Studies. Journal of Applied Polymer Science. , 103, 909-916.

[103] Reed, A. M, \& Gilding, D. K. (1981). Biodegradable polymers for use in surgerypoly(glycolic)/poly(lactic acid) homo and copolymers: 2. In vitro degradation. Polymer. , 22, 494-498.

[104] Reiners, R. A, Wall, J. S, \& Inglett, G. E. (1973). Corn Proteins: Potential for Their Industrial Use. In Industrial Uses of Cereals, ed., Y. Pomeranz, St. Paul, MN. ( American Association of Cereal Chemists., 285-298.

[105] Ren, M, Song, J, Song, C, Zhang, H, Sun, X, Chen, Q, Zhang, H, \& Mo, Z. (2005). Crystallization kinetics and morphology of poly(butylene succinate-co-adipate). Journal of Polymer Science Part B: Polymer Physics. , 43(22), 3231-3241.

[106] Rezwan, K, Chen, Q. Z, Blaker, J. J, \& Boccaccini, A. R. (2006). Biodegradable and bioactive porous polymer/inorganic composite scaffolds for bone tissue engineering. Biomaterials. , 27, 3413-3431. 
[107] Santerre, J. P, Woodhouse, K, Laroche, G, \& Labow, R. S. (2005). Understanding the biodegradation of polyurethanes: from classical implants to tissue engineering materials. Biomaterials. , 26, 7457-7470.

[108] Savenkova, L, Gercberga, Z, Nikolaeva, V, Dzene, A, Bibers, I, \& Kalmin, M. (2000). Mechanical properties and biodegradation characteristics of poly-(hydroxy butyrate)-based films. Process Biochemistry. , 35, 573-579.

[109] Shalaby, S. W. DuBose, J.A., and Shalaby, M. ((2004). Chitosan-based systems. In Absorbable and Biodegradable Polymers. Shalaby, S. W. B., and Karen, J. L., eds. (CRC Press, Boca Raton, FL., 77.

[110] Shi, C, Zhu, Y, Ran, X, Wang, M, Su, Y, \& Cheng, T. (2006). Therapeutic potential of chitosan and its derivatives in regenerative medicine. Journal of Surgery Research. , $133,185-92$.

[111] Shiku, Y, Hamaguchi, P. Y, Benjakul, S, Visessanguan, W, \& Tanaka, M. (2004). Effect of surimi quality on properties of edible films based on Alaska Pollack. Food Chemistry. , 86, 493-499.

[112] Sienkiewicz, T, \& Riedel, C. L. (1990). Utilization of Whey. In Whey and Whey Utilization, Second Edition. eds., T. Sienkiewicz and C-L. Riedel, Gelsenkirchen-Buer ( Germany: Verlag Th. Mann., 92-130.

[113] Sinha, V. R, Bansal, K, Kaushik, K, Kumria, R, \& Trehan, A. (2004). Poly- - -caprolactone microspheres and nanospheres: an overview. International Journal of Pharmaceutical. 278: 123.

[114] Slade, L, \& Levine, H. (1987). Polymer-Chemical Properties of Gelatin in Foods. In Advances in Meat Research, eds., A.M. Pearson, T.R. Dutson and A.J. Bailey ( New York: Van Nostrand Reinhold Company., 4, 251-266.

[115] Smith, R. (2005). Biodegradable polymers for industrial applications. ( Woodhead Publishing., 223-226.

[116] Sodian, R, Hoerstrup, S. P, Sperling, J. S, Martin, D. P, Daebritz, S, Mayer, J. E, \& Vacanti, J. P. (2000). Evaluation of biodegradable, three-dimensional matrices for tissue engineering of heart valves. ASAIO Journal. , 46, 107-110.

[117] Soy Protein Council (1987). Soy Protein Products: Characteristics, Nutritional Aspects, and Utilization. Washington, DC.

[118] Steeves, D. M, Farrell, F, \& Ratto, J. A. (2007). Investigation of Polybutylene Succinate-co-Adipate (PBSA)/Montmorillonite Layered Silicate (MLS) Melt-Processed Nanocomposites. Journal of Biobased Materials and Bioenergy. , 1, 94-108.

[119] Sun, R. C, \& Tomkinson, J. (2000). Essential guides for isolation/purification of polysaccharides. Encylopaedia Seperation Science. , 6, 4568-4574. 
[120] Suyatama, N. E, Tighzert, L, \& Copinet, A. (2005). Effects of hydrophilic plasticizers on mechanical, thermal, and surface properties of chitosan Films. Journal of Agricultural and Food Chemistry. , 53, 3950-3957.

[121] Thakore, I. M, Desai, S, Sarawadade, B. D, \& Devi, S. (2001). Studies on biodegradability, morphology and thermomechanical of LDPE/modified starch blends. European Polymer Journal. , 37, 151-160.

[122] Tharanathan, R. N. (2003). Biodegradable films and composite coatings: past, present and future. Trends in Food Science \& Technology. , 14, 71-78.

[123] Tian, H, Tang, Z, Zhuang, X, Chen, X, \& Jing, X. (2012). Biodegradable synthetic polymers: Preparation, functionalization and biomedical application. Progress in Polymer Science. , 37, 237-280.

[124] Vercauteren, F, \& Donners, W. A. B. (1986). A C nuclear magnetic resonance study of the microstructure of poly (vinyl alcohol). Polymer. , 27, 567-578.

[125] Vert, M. (2005). Aliphatic polyesters: great degradable polymers that cannot do everything. Biomacromolecules. , 6, 538-546.

[126] Watt, I. C. (1983). The Theory of Water Sorption by Biological Materials. In Physical Properties of Foods. eds., R. Jowitt, F. Escher, B. Hallstrom, H.F.T. Meffert,W.E.L. Spiess and G. Vos. ( London, England: Applied Science Publishers., 27-41.

[127] Wiedersheim, W, \& Strobel, E. (1991). Compounding of thermoplastic starch with twin screw extruders. Starch/Stärke. , 43, 138-145.

[128] Witherly, S. A. (1990). Soy Formulas Are Not Hypoallergenic. American Journal of Clinical Nutrition. , 51, 705-706.

[129] Wolf, W. J. (1972). Purification andproperties of the proteins. In Soybeans: Chemistry and technology. eds. A.K. Smith, and S.J. Circle. ( Westport, CN: The Avi Publishing Company, Inc., 93-143.

[130] Wrigley, C. W, \& Bietz, J. A. (1988). Protein and Amino Acids. In Wheat Chemistry and Technology. ed.,Y. Pomeranz, St. Paul,MN. ( American Association of Cereal Chemists., 159-275.

[131] Xiong, H. Tang, Sh., Tang, H. and Zou, The structure and properties of a starchbased biodegradable film. Carbohydrate Polymers. 71: 263-268., 2008.

[132] Yamauchi, K, \& Khoda, A. (1997). Novel Proteinous Microcapsules from Wool Keratins. Colloids and Surfaces B: Biointerfaces. , 9, 117-119.

[133] Yamauchi, K, Yamauchi, A, Kusunoki, T, Khoda, A, \& Konishi, Y. (1996). Preparation of Stable Aqueous Solution of Keratins, and Physicochemical and Biodegradational Properties of Films. Journal of Biomedical Materials and Resourses. , 31, 439-444. 
[134] Yang, X, Zhao, K, \& Chen, G. Q. (2002). Effect of surface treatment on the biocompatibility of microbial polyhydroxyalkanoates. Biomaterials. , 23, 1391-1397.

[135] Yoshie, N, Saito, M, \& Inoue, Y. (2004). Effect of chemical compositional distribution on solid-state structure and proeprties of poly(3-hydroxybutyrate-co-3-hydroxyvalerate). Polymer. , 45, 1903-11.

[136] Yu, L, Dean, K, \& Li, L. (2006). Polymer blends and composites from renewable resources. Progress in Polymer Science. , 31, 576-602.

[137] Zilberman, M, Nelson, K. D, \& Eberhart, R. C. (2005). Mechanical properties and in vitro degradation of bioresorbable fibers and expandable fiber-based stents. Journal of Biomedical Material Research. Part B: Appled Biomaterials. , 74, 792-799. 
